\title{
PACAP ameliorates the fertility of obese mice through PAC1/PKA/ERK/Nrf2 signal axis
}

\author{
Wailan Shan $\mathbb{D}^{1,2}$, Shiyin Lu1,2, Biqian Ou1,2, Jia Feng1,2, Zixian Wang1,2, Huixian Li1,2, Xiaohua Lu³ and Yi Ma1,2 \\ ${ }^{1}$ Institute of Biomedicine, Department of Cellular Biology, Jinan University, Guangzhou, China \\ ${ }^{2}$ National Engineering Research Center of Genetic Medicine, Key Laboratory of Bioengineering Medicine of Guangdong Province, Jinan University, \\ Guangzhou, China \\ 3The First Affiliated Hospital of Jinan University, Guangzhou, China
}

Correspondence should be addressed to Y Ma: 1830514160@qq.com

\begin{abstract}
Obesity is strongly linked to male infertility. Apoptotic inflammatory response caused by oxidative stress in testicular spermatogenic cells is one of the important causes of obesity-related male infertility. As bioactive peptide is secreted by the pituitary gland, pituitary adenylate cyclase activating polypeptide (PACAP) has a powerful triple role of anti-oxidation, anti-apoptosis, and anti-inflammation, and it is involved in the male reproduction regulation, but the specific mechanism remains unknown. The purpose of this study is to explore the role of PACAP in obesity-related male infertility. In cellular level experiments, mouse spermatocytes (GC-2) were treated with palmitate (PA) to establish an high-fat injury cell model in vitro and then treated with PACAP. In animallevel experiments, C57BL/6 male mice were fed with a high-fat diet (HFD) to induce obesity and subsequently treated with PACAP. The cell mechanism studies show that PACAP selectively binded to the PAC1 receptor to attenuate palmitic acid-induced mouse spermatogenic cell (GC-2) oxidative damage and apoptotic inflammatory response via the PKA/ERK/Nrf2 signaling axis. However, this mechanism was inhibited in GC-2 cells inhibiting the activity of Nrf2. The animal experiment studies show that PACAP treatment ameliorated obesity characteristics, including body weight, epididymal adipose weight, testes/body weight, serum lipids levels, and reproductive hormone levels in vivo.

Additionally, PACAP was shown to improve the reproductive function of the obese mice, which was characterized by improved testis morphology and sperm parameters via Keap1/Nrf2/ARE pathway. These beneficial effects of PACAP were abolished in obese mice with testes-specific knockdown of Nrf2. Our data suggested that PACAP could ameliorate fertility in obese male mice and may be a promising candidate drug for obesity-induced male infertility.
\end{abstract}

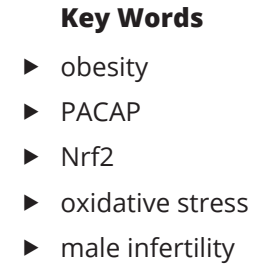

Journal of Endocrinology (2021) 248, 337-354

\section{Introduction}

As the incidence of obesity induced by overnutrition continues to increase, the incidence of metabolic syndrome and some common metabolic diseases such as hypertension, coronary heart disease, and type 2 diabetes, which are often complicated or caused by obesity, are also on the rise (Caballero 2007, Cabler et al. 2010). In addition to complications such as cardiovascular diseases, scientists have recently begun to realize that people with obesity or overweight showed an increasing incidence of infertility, and some manifestations of paternal obesity may have a 
negative impact on basic sperm parameters, such as total sperm concentration and motility (Hammoud et al. 2008, Palmer et al. 2012).

Obesity can cause disturbance of the endocrine axis and affect male sex hormone secretion. In obese patients, the concentration of testosterone, gonadotropin and inhibin B are decreased and estrogen are increased (Kley et al. 1980). In addition, many studies have shown a relationship between fat abnormalities and infertility, but the detailed mechanism is still unclear (Ramírez-Torres et al. 2000, Shalaby et al. 2004). Excessive accumulation of fat in the testis and epididymis can directly lead to abnormal structure of the testis and epididymis and also release inflammatory factors, reactive oxygen species (ROS) and oxidative free radicals, affecting the endocrine function of testicular tissue, which have varying degrees of impact on both cell proliferation and spermatogenesis (Bachir \& Jarvi 2014). More and more studies have shown that obesity has a significant negative effect on the male reproductive system (Galliano \& Bellver 2013, Landry et al. 2013). Compared with those of a normal body weight, obese patients are more likely to accumulate ROS, leading to oxidative stress (Halliwell \& Cross 1994). Oxidative stress is considered to play an important role in nutritional obesity-induced male infertility, which is one of the important reasons for obesity-induced male infertility, therefore, an important measure to prevent the occurrence of nutritional obesity-induced male infertility is to improve the antioxidant capacity of the patient's testicular tissue (Liu et al. 2020).

Therefore, there is an urgent need to find effective ways to prevent and treat obesity-induced male infertility. Many studies have found that pituitary adenylate cyclase activating polypeptide (PACAP), a potentially valuable neuroprotective peptide, has two forms: PACAP38 and PACAP37. They have similar biological activities and play an important role in anti-oxidation, anti-apoptosis and anti-inflammation (Dohi et al. 2002). PACAP and its receptors, PAC1, VPAC1 and VPAC2, are widely distributed in the CNS and peripheral tissues, especially in the brain, pancreas, fat, muscle and testis (Vaudry et al. 2009, Douiri et al. 2016). Moreover, testicular germ cells contain PAC1 receptors predominantly (Arimura 1992). Tanii et al. has found that PACAP could promote spermatogenesis in mice testes, improve sperm motility and ability to penetrate oocytes, and promote fertilization (Tanii et al. 2011). Reglodi et al. have found that PACAP promoted the expression of testosterone, collagen IV, and collagen IX through the PAC1-PKA-Sox9 axis and was involved in regulating the proliferation of spermatogenic cells, sperm motility, and the formation of the blood-testis barrier (Reglodi et al. 2018). In short, PACAP is closely related to male infertility and can be used as a promising candidate drug to improve obesity-related male infertility.

The antioxidant signaling pathway Keap1/Nrf2/ARE is one of the important defensive transduction pathways for the body to resist internal and external environmental stress. The vicious cycle of oxidative stress and proinflammatory cytokine overexpression could be inhibited by activation of the Nrf2 signaling pathway (Itoh et al. 2010). Other experiments have shown that the antioxidant capacity of Nrf2 signaling pathway played a more important role in anti-apoptosis (Khodagholi \& Tusi 2011). Besides, Keap1/Nrf2/ARE signaling pathway was activated in reproductive system diseases (Agarwal et al. 2018). Human sperm are particularly sensitive to oxidative stress, which is an important cause of male infertility. Enhancing Nrf2 expression helped reduce oxidative stress in patients with obesity (Liu \& Ding 2017, Agarwal et al. 2018). Studies have shown that abnormal sperm morphology and function were related to increased production of reactive oxygen species (ROS) and decreased antioxidant status (i.e. oxidative stress) (Durairajanayagam et al. 2014). Nrf2 plays a key role in cellular antioxidant defense, thereby protecting the male reproductive tract from oxidative stress. The lack of Nrf2 function has a damaging effect on Nrf2-/- mouse Sertoli cells and germ cells, as well as on the epididymal stage of sperm maturation, and exhibits decreased sperm count and sperm motility (Nakamura et al. 2010). Nrf2 controls the activity of enzymes and transporters in the blood-testis barrier and provides functional protection for the male reproductive system. Kang Chen et al. recruited 55 patients with weak and oligospermia, and 65 controls, and demonstrated low expression of Nrf2 mRNA in sperm of men with low sperm motility (Aitken et al. 1996). The Keap1/Nrf2/ARE signaling pathway plays a key role in the oxidative stress response, and Nrf2 is considered to be a transcription factor that promotes the expression of many important antioxidant genes (Kensler et al. 2007, Yu et al. 2013). Its downstream protein HO-1 is key in the male reproductive system and sexual dysfunction (Shamloul 2009). The Keap1/Nrf2/ ARE signaling pathway and its regulated antioxidant enzymes have been shown to play a key role in the defense of cellular oxidative stress during spermatogenesis and fertilization (Kensler et al. 2007, Nakamura et al. 2010). The antioxidant enzymes and molecules regulated by this pathway, such as superoxide dismutase (SOD), glutathione (GSH), glutathione peroxidase (GPX) and catalase (CAT), are abundant in semen plasma or sperm cells (Jeulin et al. 1989, Aitken et al. 1996, Meseguer et al. 2007) and affect 
male fertility in different ways. We hypothesized that Nrf2 may be a promising therapeutic target for obesity-related male infertility. Taken together, PACAP and Nrf2 have been shown to alleviate obesity-related comorbidities. Nevertheless, there are no studies that investigate whether Nrf2 mediates the effects of PACAP in obesity-related male infertility.

Although there is growing evidence that obesity is an important cause of male infertility, its exact mechanism of action remains unclear. In this study, we demonstrated that activation of Nrf2 by PACAP in the form of PACAP38 alleviates impairment of spermatocyte (GC-2) induced by high fat at the cellular level. However, these beneficial effects are abolished in GC-2 cells with specific inhibition of Nrf2 activity. Moreover, we show that the protective effects of PACAP in the mouse spermatocyte cells (GC-2) were also present on spermatogenic damage identified in the obese mouse model. These helped us to explain the pathogenesis of reproductive injury in obese male mice, which provide theoretical basis and experimental reference for the diagnosis of clinically obesity-related male infertility and future drug treatment.

\section{Materials and methods}

\section{Cell culture}

The mice spermatocyte GC-2 cells (ATCC) were cultivated in Dulbecco's Modified Eagle's Medium (DMEM) (Gibco) containing 10\% fetal bovine serum (FBS) (Thermo Fisher Scientific) and $1 \%$ penicillin streptomycin (Thermo Fisher Scientific) in an incubator supplied with 95\% air and 5\% $\mathrm{CO}_{2}$ at $37^{\circ} \mathrm{C}$. The medium was replaced every 3 days, and cells were subcultured by treatment with $0.05 \%$ trypsinEDTA (Invitrogen) for $1 \mathrm{~min}$. Cells were cryopreserved in a frozen solution containing $600 \mu \mathrm{L}$ of medium, $300 \mu \mathrm{L}$ of FBS, and $100 \mu \mathrm{L}$ of DMSO (Sigma-Aldrich).

\section{Cell viability assay}

The GC-2 cell line was derived from mouse spermatocyte and has been widely used as a source of spermatocyte for in vitro studies. It is well known that PA is one of the most abundant free fatty acids (FFAs) in serum. Due to the close relationship between rising serum FFA levels and obesity (Manco et al. 2000), PA injuried in vitro cell models were established to mimic the conditions of obesity in vivo, as previously reported (Kuwabara et al. 2015). To mimic the in vivo obesity conditions in vitro, a damaged GC-2 cell model was established by using palmitic acid (PA) (Kunchuang Technology Development Co., Ltd., Xian, China). The GC-2 cells were seeded onto a 96-well plate at a density of $1.5 \times 10^{4}$ cells/well in DMEM medium. After $70 \%$ of the cells adhered to the wall, they were incubated with various concentration of $\mathrm{PA}(0,100,200,300,400,500$ and $600 \mu \mathrm{M})$ for $1,3,6,12,18,24$ and $48 \mathrm{~h}$, respectively. The cells which were not treated with PA were used as normal control (NC). The cell viability in each experimental group was determined via the CCK-8 assay (Sigma-Aldrich). The groups with cell viability of approximately $60 \%$ were further used to establish the PA-injury GC-2 cell model. After the PA-injured GC-2 cell model was established, the cells were incubated with phosphate buffered saline (PBS) or various concentrations of PACAP $(0.0001,0.001,0.01$, $0.1,1$, and $10 \mu \mathrm{M})$ (GL Biochem Ltd, Shanghai, China) for an additional $24 \mathrm{~h}$. The cells incubated without PA and PACAP were used as normal control (NC). The proliferation rate in each experimental group was determined using a CCK-8 assay. For the receptor blocking experiments, GC-2 cells were preincubated with $1 \mu \mathrm{M}$ of MAX.D4 (a specific PAC1 receptor antagonist) (Sigma Aldrich), $1 \mu \mathrm{M}$ of PG97-269 (a specific VPAC1 receptor antagonist) (Sigma Aldrich), and $1 \mu \mathrm{M}$ of PG99-465 (a specific VPAC2 receptor antagonist) (Sigma Aldrich) at $37^{\circ} \mathrm{C}$ for $30 \mathrm{~min}$ before being treated with $100 \mathrm{nM}$ of PACAP. The cell viability rate in each experimental group was also determined using the CCK-8 assay, that is, after the cell treatment time, $10 \mu \mathrm{L}$ CCK-8 solution was added to each well (four replicates per group), incubated in a $37^{\circ} \mathrm{C}$ incubator for $30 \mathrm{~min}$, and then the absorbance was measured at $450 \mathrm{~nm}$ with a microplate reader. Finally, the proliferation rate of GC-2 cells was calculated according to the OD value of each group.

\section{Detection of ROS in cells}

The levels of intracellular ROS were detected by the fluorescent probe 2',7'-dichlorfluorescein-diacetate (DCFHDA) kit (KeyGEN BioTECH, Jiangsu, China) according to the manufacturer's instructions. The GC-2 cells were seeded onto a six-well plate at a density of $5 \times 10^{5}$ cells/well in DMEM medium. After 70\% of the cells adhered to the wall, they were incubated with $400 \mu \mathrm{M}$ of PA. After exposure to PA for $12 \mathrm{~h}$ and treatment with PACAP for $24 \mathrm{~h}$, the cultured GC-2 cells were washed twice with phosphatebuffered saline (PBS), and then incubated with $10 \mu \mathrm{M}$ DCFH-DA in medium at $37^{\circ} \mathrm{C}$ for $20 \mathrm{~min}$ in darkness. After cells were washed three times with serum-free medium, the fluorescence intensity was immediately measured using a flow cytometer (excitation at $488 \mathrm{nM}$, emission at $525 \mathrm{nM}$ ) 
(Becton, Dickinson and Company, USA) by digesting and collecting the cells (about 20,000 cells per group) or directly via a fluorescence microscope (Nikon Ti).

\section{Measurement of malondialdehyde (MDA) and antioxidant enzymes}

After exposure to PA for $12 \mathrm{~h}$ and treatment with PACAP for $24 \mathrm{~h}$, the cultured GC-2 cells were harvested, sonicated and centrifuged to collect the supernatant. The levels of malondialdehyde (MDA), antioxidant enzymes such as superoxide dismutase (SOD), and glutathione peroxidase (GPx) were then measured using their respective assay kits (Jiancheng Bioengineering Institute, Nanjing, China) according to the manufacturer's instructions. MDA was evaluated by thiobarbituric acid (TBA) method as commercially recommended (Nanjing Jiancheng Bioengineering Institute, China). The method was based on the spectrophotometric measurement of the color produced during the reaction to TBA with MDA. MDA concentrations were calculated by the absorbance of TBA reactive substances (TBARS) at $532 \mathrm{~nm}$. SOD activity was assayed using the xanthine/xanthine oxidase method based on the production of $\mathrm{O}^{2-}$ anions. GPX activity was estimated based on its catalyzation by the oxidation of reduced glutathione in the presence of cumene hydroperoxide. The generation of NAD phosphate was measured spectrophotometrically at $340 \mathrm{~nm}$.

\section{Cell apoptosis assay}

Cell apoptosis was measured using the annexin V-FITC apoptosis detection kit (Ebioscience, USA) according to the manufacturer's recommendations. The GC-2 cells were seeded onto a six-well plate at a density of $5 \times 10^{5}$ cells/ well in DMEM medium. After $70 \%$ of the cells adhered to the wall, they were incubated with $400 \mu \mathrm{M}$ of PA. After exposed to PA for $12 \mathrm{~h}$ and treated with PACAP for $24 \mathrm{~h}$, the GC-2 cells were collected by trypsinization and washed with cold PBS. After centrifugation at $100 \boldsymbol{g}$ for $3 \mathrm{~min}$, the cells were resuspended in binding buffer and then incubated with FITC-labeled Annexin V and propidium iodide (PI) for $15 \mathrm{~min}$ in the dark, and 20,000 cells were taken from each group for flow analysis within $1 \mathrm{~h}$.

\section{Protein extraction and western blotting}

Protein was extracted from frozen testicular samples or cultured GC-2 cells by using RIPA lysis buffer $(50 \mathrm{mM}$ Tris-HCl (pH 8.0), $150 \mathrm{mM} \mathrm{NaCl}, 1 \% \mathrm{NP}-40,0.5 \%$ sodium deoxycholate and 0.1\% SDS) (Beyotime) supplemented with $1 \%$ protease inhibitor (Beyotime), 1\% phosphatase inhibitor (Beyotime) and 1\% phenylmethanesulfonyl fluoride (PMSF) (Beyotime). It was then quantitated by BCA protein assay kit (Thermo). In total, 20-30 $\mu \mathrm{g}$ of protein was loaded onto a $12 \%$ SDS-polyacrylamide gel, and separated proteins were transferred to PVDF membranes (Pall, USA). After blocking with 5\% BSA at room temperature for $1 \mathrm{~h}$, membranes were incubated with specific antibodies as follows: GAPDH $(1: 8000$, CST), Nrf2 (1:1000, CST), ERK (1:1000, Abcam), p-ERK (1:1000, Abcam), HO-1 (1:1000, Abcam), NQO1 (1:1000, Abcam), Keap1 (1:1000, Santa Cruz), IL-6 (1:1000, Santa Cruz), TNF $\alpha$ (1:1000, Santa Cruz), PKA (1:1000, CST), p-PKA (1:1000, CST), cleaved caspase 3 (1:1000, CST), Bcl-2 (1:1000, Abcam) and Bax (1:1000, CST). The membranes were then incubated with the appropriate horseradish peroxide (HRP)-conjugated secondary antibodies for an additional $1 \mathrm{~h}$ at room temperature. The protein bands were visualized using West Pico Chemiluminescent Substrate (Thermo Fisher Scientific). Grayscale analysis of Western blot results was performed using ImageJ software (NIH) (Liu et al. 2014). Extraction of Nrf2 nuclear protein with nuclear protein extraction kit (Cell Signaling Technology, Inc.).

\section{Animals and treatment}

All animal experiments were in accordance with the use of laboratory animals. The housing and related procedures were approved by the Laboratory Animal Ethics Committee of Jinan University, China. C57BL/6J mice (SPF grade, male, approximate 6 weeks of age, weighing about 20 g) were purchased from Pengyue Experimental Animal Breeding Co., Ltd (Jinan, China). All mice were housed in individually ventilated cages and maintained on a $12 \mathrm{~h}$ light: $12 \mathrm{~h}$ darkness cycle. The mice were fed standard chow (control diet, CD; catalog number: TP2330055AC, fat calories 10\%, carbohydrate calories 75\%, and protein calories 15\%; Trophic Animal Feed High-tech Co., Ltd, Nantong, China) ( $n=10$ per group) or high-fat diet (HFD, research diets; catalog number: TP2330055A, fat calories $60 \%$, carbohydrate calories $25 \%$, and protein calories 15\%; Trophic Animal Feed High-tech Co., Ltd, Nantong, China) ( $n=40$ per group) at random for 4 weeks, and changes in body weight and food intake were monitored weekly. When the mice in the HFD group weighed $20 \%$ more than the body weight of the CD group, it was determined that the obese mice were successfully modeled (Sato et al. 2002, Yoo et al. 2011, 
Liu et al. 2016). Subsequently, part of mice fed with HFD were intraperitoneally injected with different concentrations of PACAP $(0.1 \mathrm{mg} / \mathrm{kg}, 0.2 \mathrm{mg} / \mathrm{kg}, 0.4$ $\mathrm{mg} / \mathrm{kg}$ ) or sterile saline (control) once a day for 4 weeks (Yada et al. 2000, Wang et al. 2014). The specific groups were as follows: (1) CD+Vehicle ( $n=10$ per group); (2) HFD+Vehicle ( $n=10$ per group); (3) HFD+0.1 mg/kg PACAP ( $n=5$ per group); (4) HFD + $0.2 \mathrm{mg} / \mathrm{kg}$ PACAP $(n=5$ per group); (5) HFD + $0.4 \mathrm{mg} / \mathrm{kg} \operatorname{PACAP}(n=20$ per group). A portion of PACAP-treated obese mice was reserved for Nrf2 lentivirus injection. Retro-orbital blood was collected from the mice, naturally coagulated at room temperature for $10-20 \mathrm{~min}$, and centrifuged at 200-300 $\boldsymbol{g}$ for $20 \mathrm{~min}$, and the supernatant was carefully collected, taking care to avoid hemolysis. Four blood lipids of triglyceride (TG), cholesterol (TC), low density lipoprotein cholesterol (LDL-C) and high density lipoprotein cholesterol (HDL-C) and four sex hormones of testosterone (T), estradiol (E2), follicle stimulating hormone (FSH) and luteinizing hormone (LH) in separated serum were measured using an automatic biochemical detector (Chemray 240, Rayto Life Technology, Shenzhen, China). The epididymal adipose and testes were taken, and epididymal adipose weight and the testicular weight/body weight ratio were calculated. All animals were euthanized by cervical dislocation, and effort was made to minimize pain and suffering.

\section{Lentiviral transfection for downregulation of Nrf2 in vivo}

Lentiviral vectors carrying the Nrf2 short-hairpin RNA (LV-Nrf2-shRNA) and scramble short-hairpin RNA (LV-ctrlshRNA), which was used as a negative control, were purchased from Cyagen Biosciences (Suzhou, China). For testis-specific knockdown of Nrf2, HFD mice received $10 \mu \mathrm{L}$ lentiviral of supernatant $\left(10^{8}\right.$ transducing units $\left./ \mathrm{mL}\right)$ by intratesticular injection under pentobarbital anesthesia (50 mg/kg, i.p.) for 1 week. The procedural details of the intratesticular injection for lentiviral transfection were as follows: mice were anesthetized via pentobarbital sodium injection (50 mg/kg, i.p.). After the scrotums were sterilized, the lower abdomen was gently pressed in the direction of the genitals to expose the testes. Next, the testes were injected with the lentiviral supernatant using gentle syringe pressure and a sharp syringe (30 G). After the injection, the needle was kept in the testes for $30 \mathrm{~s}$ and then was slowly removed to prevent the injected material from spilling. Finally, the mice were put in the specific-pathogen-free animal room and allowed to awaken naturally.

\section{Detection of ROS in mouse sperm}

The levels of ROS in mouse sperm were detected by the sperm cell oxidative stress reactive oxygen species (ROS) NBT colorimetric quantitative detection kit (MingXiu BioTECH, Shanghai, China) according to the manufacturer's instructions. Two millilitre of freshly collected (within $1 \mathrm{~h}$ ) semen was pipetted into a $2 \mathrm{~mL}$ centrifuge tube and incubated in a $37^{\circ} \mathrm{C}$ incubator for $20 \mathrm{~min}$. Then centrifuged in a mini-tabletop centrifuge for $7 \mathrm{~min}$ at a speed of $300 \mathrm{~g}$. The supernatant was carefully removed, $2 \mathrm{~mL}$ of cleaning solution was added (Reagent A), the sperm cell pellets were mixed, and centrifuged for $7 \mathrm{~min}$ in a benchtop centrifuge at a speed of $300 \mathrm{~g}$. The supernatant was carefully removed, added an appropriate amount of cleaning solution (Reagent A) was added, mixed well, sperm cells on the hemocytometer were counted, the sperm cell count was adjusted to $1 \times 10^{7} / \mathrm{mL}$, and put it in the $37^{\circ} \mathrm{C}$ incubator for use (within $1 \mathrm{~h}$ ). Before the start of the experiment, $10 \mathrm{~mL}$ of cleaning solution (Reagent A) was removed into a bottle of staining solution (Reagent B). After mixing, it was marked as dyeing working solution and placed in the ice tank for later use. Hundred microliters of the pretreated mouse sperm cells was pipetted into a $1.5 \mathrm{~mL}$ centrifuge tube, $100 \mu \mathrm{L}$ of staining working solution was added, mixed well, and incubated in a $37^{\circ} \mathrm{C}$ cell incubator for $45 \mathrm{~min}$. Then centrifuged in a mini-tabletop centrifuge for $10 \mathrm{~min}$ at a speed of $500 \boldsymbol{g}$. The supernatant was carefully removed, added $500 \mu \mathrm{L}$ of cleaning solution (Reagent A), and centrifuged for $10 \mathrm{~min}$ at a speed of $500 \boldsymbol{g}$ in a micro bench top centrifuge. The cleaning solution was carefully removed and the previous experiment step was repeated once. Hundred microliters of dissolving solution (Reagent C) was added and mixed well, incubated for 5 min at room temperature, immediately transfered to a 96-well plate, put in a microplate reader and the active oxygen absorbance (OD) at a wavelength of $650 \mathrm{~nm}$ was measured.

\section{Semen analysis in mice}

The sperm was acquired by puncturing the cauda epididymides and squeezing the vas deferens into a petri dish containing $1 \mathrm{~mL}$ of G-IVFTM PLUS medium (Vitrolife, Sweden). The sperm of epididymis and vas deferens of each group of mice were tested with computer-assisted sperm analyzer system (CASA; Microptic Co., Barcelona, Spain). Ten microliters of sperm was added to a special sperm counting board, and the CASA system automatically calculated the semen concentration and analyzed the 
sperm motility. At least five fields of vision was imaged with more than 200 sperm per test. The Diff-Quick Stain Kit (Huakang Co., Ltd., Shenzhen, China) recommended by WHO was used for sperm morphology analysis (Lu et al. 2010). Individual sperm morphology was scored as head defects, neck defects, tail defects or normal, as a percentage of each form. All of the previously mentioned methods were performed on at least 200 sperm cells and at least three repetitions of each sample were analyzed.

\section{Histological analysis}

For HE staining, the testis and epididymal adipose tissues of each group were fixed by $4 \%$ paraformaldehyde, embedded in paraffin, and cut into 5 um sections. Dewaxing, dexylene, dyeing, counterstaining, dehydration, solid sealing, etc., were carried out, and the pathological changes of testis and epididymal adipose tissues of each group were then observed under a light microscope (Nikon Ti).

\section{Statistical analysis}

Quantitative results are expressed as $\bar{x} \pm$ s.D. of at least three independent experiments. All data in this study were statistically analyzed using SPSS 19.0 and GraphPad Prism 6 software. Statistical differences between two groups were determined by Student's $t$ test. One-way ANOVA was used for comparisons among different groups. $P$-value $<0.05$ wasconsideredstatisticallysignificant. ${ }^{*} P<0.05$, ${ }^{* *} P<0.01,{ }^{* *} P<0.001$.

\section{Results}

\section{PACAP promoted the proliferative activity of PA-injured GC-2 cells}

We chose the GC-2 cell line to investigate whether PACAP was protected against PA-induced injury in vitro. Our experimental results indicated that the viability rate was approximately $60 \%$ when the cells were incubated with $400 \mu \mathrm{M}$ of PA for $12 \mathrm{~h}$ (Fig. $1 \mathrm{~A}$ and B). Based on the principle of LD50, we chose $400 \mu \mathrm{M}$ PA for $12 \mathrm{~h}$ to establish a GC-2 high-fat injury cell model. PACAP has a protective effect on PA-injured cells. When the PACAP concentration was $0.1 \mu \mathrm{M}$, the cell proliferation effect was the most obvious, and it returned close to the level of the NC group, which was significantly different compared with the PA group (Fig. 1C). Therefore, we chose $0.1 \mu \mathrm{M}$
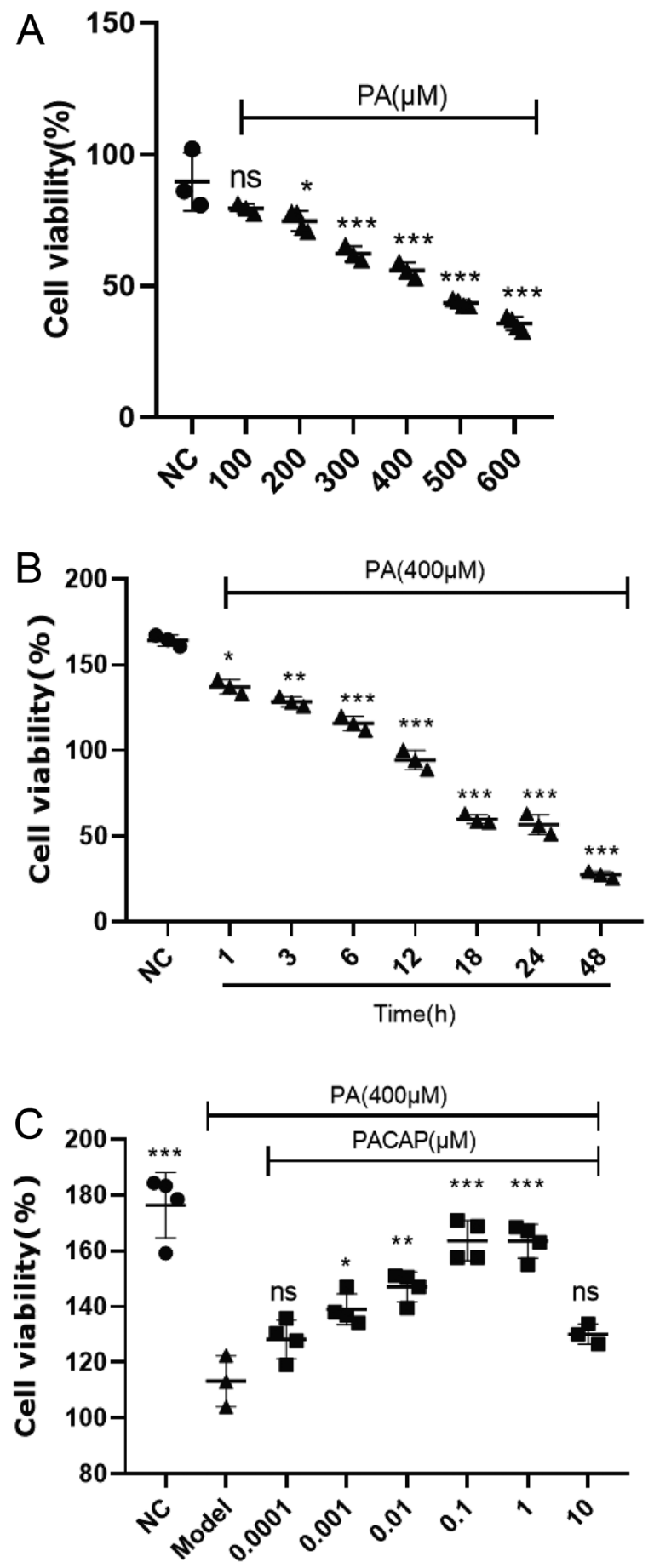

Figure 1

PACAP improved viability of PA-injured GC-2 cells. (A and B) Effects of PA on GC-2 cell viability. Cells were incubated with or without PA at various concentrations and times. Cell viability rate $(\%)=$ average $\mathrm{OD}_{450}$ of each experimental group/average $\mathrm{OD}_{450}$ of control group. (C) The cell viability of the PA-injured GC-2 cell model treated with PACAP. Viability rates of PA-induced GC-2 cells treated with PBS or $0.0001,0.001,0.01,0.1,1$, and $10 \mu \mathrm{M}$ PACAP for $24 \mathrm{~h}$. The cells without PA and PACAP were used as control. $* P<0.05, * * P<0.01, * * * P<0.001$, vs NC or PA; ns, no significant difference. Data are presented as means \pm s.D. PA, palmitic acid; PACAP, pituitary adenylate cyclase activating peptide. 
PACAP for $24 \mathrm{~h}$ as the best repair condition for GC-2 cells with high-fat injury. Our data indicated that PACAP significantly promoted GC-2 cells proliferation after PA-induced injury.

\section{PACAP alleviated PA-induced oxidative stress, apoptosis and inflammatory responses in GC-2 cells}

Obesity induced oxidative stress and produced large amounts of ROS, which led to oxidative damage in spermatogenic cells (Meigs et al. 2007, Seo et al. 2014). The experimental results show that $100 \mathrm{nM}$ of PACAP significantly reduced ROS levels in $400 \mu \mathrm{M}$ PA-induced GC- 2 cells, and restored it to the NC level. The fluorescence detection results were consistent with flow cytometry results (Fig. 2A and B). The level of SOD activity and GPX level indirectly reflected the body's ability to scavenge free radicals, and the level of MDA indirectly reflected the severity of the body's cells being attacked by free radicals (Marzec-Wróblewska et al. 2011). The results show that PACAP increased SOD activity and GSH-PX content and decreased MDA levels in PA-injured GC-2 cells (Fig. 2C, D and $\mathrm{E}$ ). The rate of apoptosis was determined using flow cytometry, while apoptosis-related protein levels were measured by Western blot analysis. The results show that PA markedly increased the apoptotic rate when compared to the control, while PACAP treatment significantly reversed PA-induced cell apoptosis (Fig. 2F). The Western blot analysis show that upregulation of cleaved caspase and Bax by PA were significantly attenuated by PACAP, meanwhile, PA-induced downregulation of Bcl-2 was also significantly ameliorated by PACAP (Fig. 2G and H). PA significantly enhanced IL-6 and TNF $\alpha$ expression compared with the normal control group, which could be significantly inhibited by PACAP treatment (Fig. 2I). These data proved that PACAP alleviated PA-induced oxidative stress, apoptosis and inflammatory responses in GC-2 cells.

\section{PACAP ameliorated PA-induced GC-2 cell injury mainly via the PAC1/PKA/ERK/Nrf2 signaling pathway}

Nrf2 acts as a transcription factor that promotes the expression of many key antioxidant genes, which play a key role in Keap1/Nrf2/ARE signaling pathways in response to oxidative stress, apoptosis and inflammatory response (Itoh et al. 2010). Therefore, we examined the expression of Nrf2 pathway-related proteins in GC-2 cells. The Western blot analysis show that in PA-injured GC-2 cells, PACAP could significantly increase Nrf2, HO-1 and
NQO1 expression and decrease Keap1 expression (Fig. 3A). To further investigate which PACAP receptor was involved in this protective effect, GC-2 cells were preincubated with three types of PACAP receptor antagonists before treatment with $100 \mathrm{nM}$ of PACAP. We found that the suppression of cell damaging effect disappeared in PA-injured GC-2 cells preincubated with $1 \mu \mathrm{M}$ of MAX. D4 (PAC1 receptor antagonist) before treatment with $100 \mathrm{nM}$ of PACAP. However, this protective effect was not nullified by PG97-269 (VPAC1 receptor antagonist) or PG99-465 (VPAC1 receptor antagonist). The results of the three PACAP receptor inhibitors on the expression of Nrf2 protein were consistent with the results on the cell proliferation (Fig. 3B). These data indicated that PACAP ameliorated PA-induced GC-2 cell damage mainly via the PACAP/PAC1/Nrf2 signaling pathway. The major downstream event following PACAP selectively binding to the PAC1 receptor was PKA phosphorylation (activation). This subsequently phosphorylated ERK, resulting in the upregulation of target genes/proteins (Dejda et al. 2008). Some studies have found that ERK could directly recognize the antioxidant regulator Nrf2 and activate Nrf2 to enter the nucleus. Our results show that PACAP increased the protein abundance of p-PKA and p-ERK in PA-injured GC-2 cells (Fig. 3C). Enhanced p-ERK further promoted the expression of downstream Nrf2 protein (Fig. 3D). Moreover, we blocked the PACAP/PKA/ERK signaling pathway with either MAX.D4 or H89 (a specific PKA inhibitor) or SCH772984 (a specific ERK inhibitor) before treatment with PACAP and subsequently measured the Nrf2 expression levels. As expected, MAX.D4, H89, and SCH772984 inhibited Nrf2 upregulation in PA-injured GC-2 cells after PACAP treatment. These data collectively demonstrated that PACAP specifically binding to PAC1 activated the PKA/ERK signaling pathway, resulting in Nrf2 upregulation, and the activation of Nrf2 further activated downstream targets, which might effectively promote cell proliferation and inhibit cell oxidative stress, apoptosis and inflammation, thus significantly facilitating the functional recovery of GC-2 cells after PA-injury.

\section{Inhibition of partial Keap1/Nrf2/ARE pathway reversed PACAP-induced protective effect to GC-2 cells in vitro}

Treating PA-injured GC-2 cells preincubated with $5 \mu \mathrm{M}$ of ML385 (a specific Nrf2 inhibitor) before treatment with $100 \mathrm{nM}$ of PACAP blocked the antioxidant effect of PACAP, indicating that PACAP resisted oxidative 

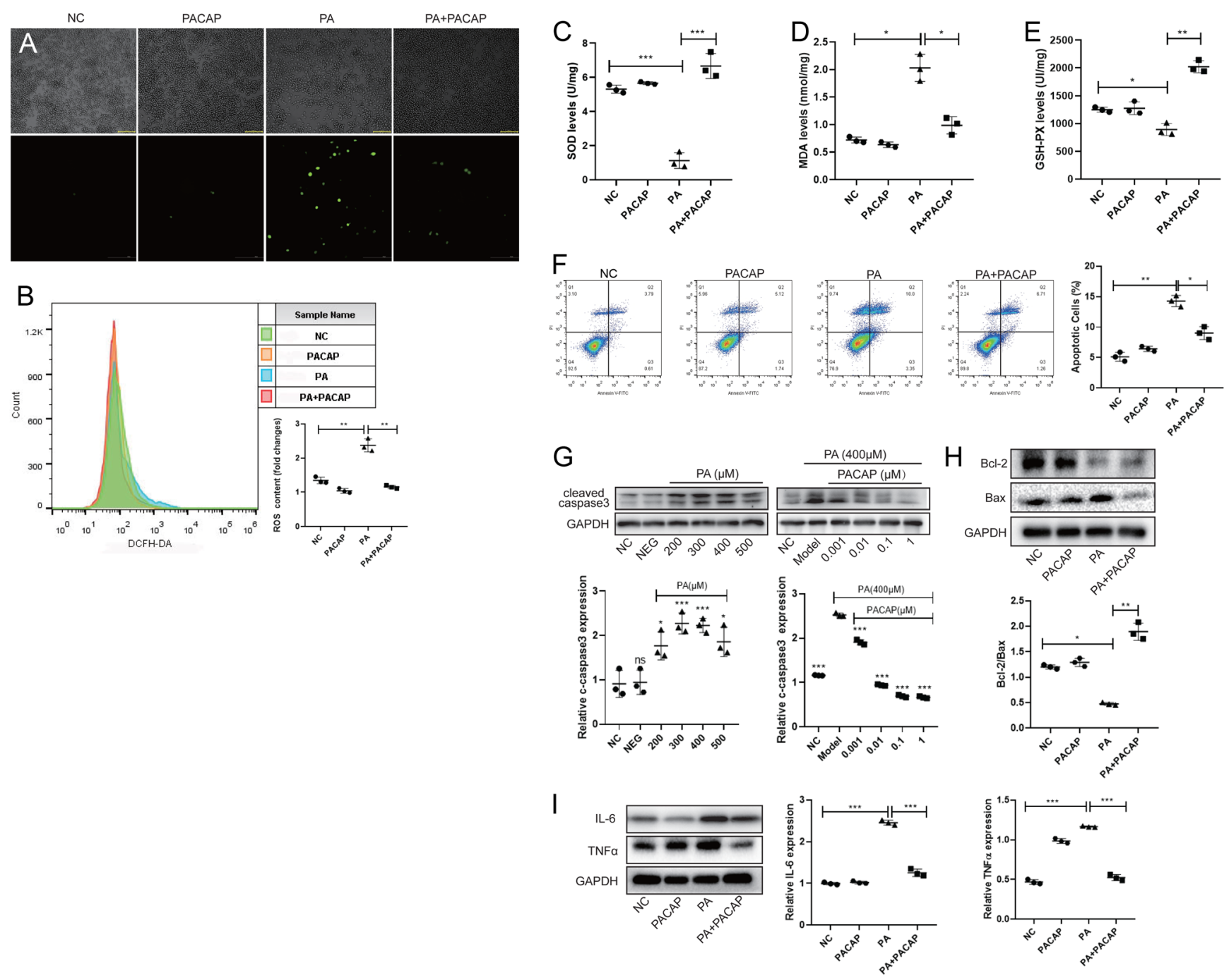

\section{Figure 2}

PACAP attenuated PA-induced GC-2 cell oxidative stress, apoptosis and inflammatory responses in vitro. (A and B) PACAP reduced ROS levels in PA-injured GC-2 cells. Qualitative analysis with fluorescence microscopy combined with flow quantitative analysis on ROS levels in GC-2 cells. (C, D and E) PACAP increased SOD and GPX activity and decreased MDA levels in PA-injured GC-2 cells. Corresponding kit was used to detect the SOD, MDA and GPX levels in GC-2 cells according to the manufacturer's instructions. (F) PACAP reduced PA-induced GC-2 cell apoptosis. Apoptosis rate of GC-2 cell were detected by flow cytometry using Annexin V-FITC/PI staining. In the images, Q4 represents normal cells, Q3 represents early apoptosis, Q2 represents late apoptosis, and Q1 represents cell debris. The apoptosis rate of cells is the combination of Q2 and Q3. (G) PACAP reduced expression of cleaved caspase3 protein in PA-injured GC-2 cells. ${ }^{*} P<0.05, * \star \star P<0.001$, PA groups with different concentrations vs NC group, NC group or different concentrations of PACAP administration groups vs model group; ns, no significant difference. $(\mathrm{H}) \mathrm{PACAP}$ reduced Bcl-2 and Bax protein expression ratio in PA-injured GC-2 cells. (I) PACAP reduced the expression of inflammation-related proteins in PA-injured GC-2 cells. $* P<0.05$, $* \star P<0.01$, $\star \star \star ~ P<0.001$, NC or PA + PACAP vs PA. Data are presented as means \pm S.D. A full color version of this figure is available at https://doi.org/10.1530/JOE-20-0316.

damage induced by PA in GC-2 cells by upregulating Nrf2 expression (Fig. 4A, B, C and D). ML385 partially offsetted the improvement effect of PACAP on PA-induced apoptosis and inflammatory response in GC-2 cells, indicating that the downregulation of Nrf2 could block the anti-apoptotic and anti-inflammatory effects of PACAP (Fig. 4E). To explore how upregulated Nrf2 regulated downstream target genes and inhibited oxidative stress, apoptosis and inflammatory responses in cells, we used
Western blot and from the results we saw that ML385 significantly decreased Nrf2 expression and increased Keap1 expression compared to PA + PACAP group, thereby attenuated the expression of downstream proteins HO-1 and NQO1, and blocked the activation of PACAP on the Keap1/Nrf2/ARE pathway. These data suggested that Nrf2 played a vital role in the antioxidant, anti-apoptotic and anti-inflammatory effects of PACAP on PA-injured GC-2 cells (Fig. 4F). 


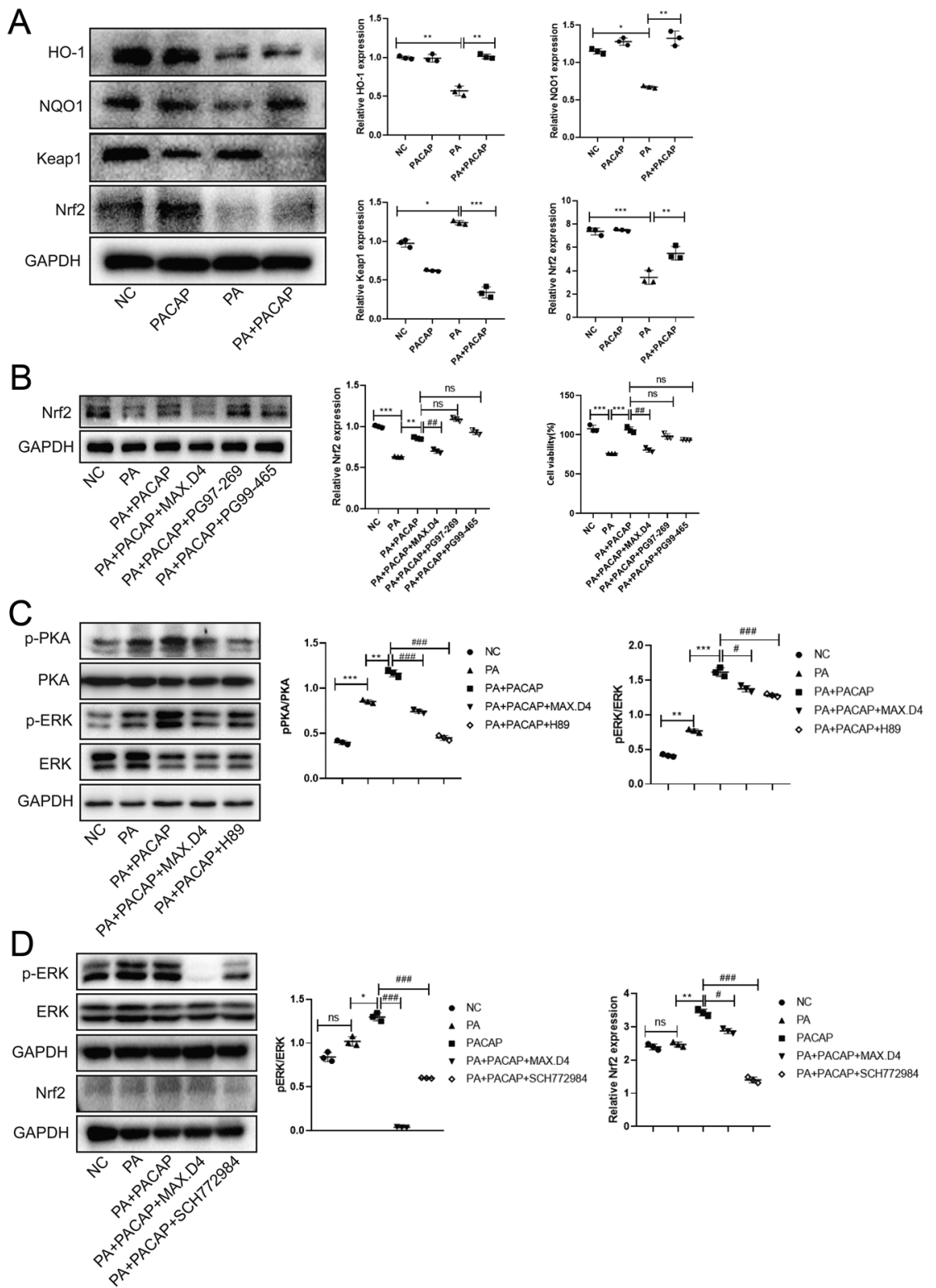

\section{Figure 3}

PACAP ameliorated PA-induced GC-2 cell injury through PAC1/PKA/ERK/Nrf2 signaling pathway. (A) PACAP activated Nrf2 signaling pathway in PA-injured GC-2 cells. (B) PACAP which selectively binds to PAC1 ameliorated GC-2 cell high-fat injury repair through regulating downstream signaling pathway. After incubating with or without $400 \mu \mathrm{M}$ of PA for $12 \mathrm{~h}, \mathrm{GC}-2$ cells were preincubated with $1 \mu \mathrm{M}$ MAX.D4, $1 \mu \mathrm{M}$ PG97-269, and $1 \mu \mathrm{M}$ PG99-465 for $30 \mathrm{~min}$ at $37^{\circ} \mathrm{C}$ prior to addition of $100 \mathrm{nM}$ of PACAP. Max.D4, a specific PACAP type I receptor (PAC1) antagonist, was used for blocking PAC1 receptor; PG97-269, a specific PACAP type II receptor (VPAC1) antagonist, was used for blocking VPAC1 receptor; PG99-465, a specific PACAP type III receptor (VPAC2) antagonist, was used for blocking VPAC2 receptor. (C and D) PACAP promoted the expression of Nrf2 via activation of PKA/ERK pathway. Activation of PKA/ERK signaling pathway contributed to PACAP-induced Nrf2 upregulation. Western blot analysis of p-PKA, PKA, ERK, p-ERK, and Nrf2 expression in normal and PA-injured GC-2 cells. The cells were preincubated with $1 \mu \mathrm{M}$ MAX.D4, $1 \mu \mathrm{M} \mathrm{H} 89$ and $2 \mu \mathrm{M} \mathrm{SCH772984} \mathrm{for} 30$ $\mathrm{min}$ at $37^{\circ} \mathrm{C}$ prior to addition of $100 \mathrm{nM}$ of PACAP, then were cultured for another $24 \mathrm{~h}$. H89 was used for blocking PKA activation, SCH772984 was used for blocking ERK activation. $* P<0.05$, $\star * P<0.01, * * * P<0.001, \mathrm{NC}$ or PA + PACAP vs PA; $\# P<0.05, \# P<0.01, \# \# P<0.001$, $\mathrm{PA}+\mathrm{PACAP}+\mathrm{MAX} . \mathrm{D} 4$ or PA + PACAP + PG97-269 or $\mathrm{PA}+\mathrm{PACAP}+\mathrm{PG} 99-465$ or $\mathrm{PA}+\mathrm{PACAP}+\mathrm{H} 89$ or $\mathrm{PA}+\mathrm{PACAP}+\mathrm{SCH} 772984$ vs PA + PACAP; ns, no significant difference. Data are expressed as mean \pm S.D.

\section{Establishment of a HFD-induced obesity mouse model}

The body weight of the male mice which were fed with HFD for 4 weeks was significantly higher than that of mice fed with a CD (Fig. 5A), while the testis volume of the male mice fed with HFD for 4 weeks was smaller than that of male mice fed with a CD (Fig. 5B). The difference in body weight between the two groups became significant after 1 week of receiving their respective diet and was maintained for the following 3 weeks. After 4 weeks of feeding in each group, the average mice body weight in the HFD group was increased by $46.7 \%(P<0.001)$ compared to that in the CD group, indicating that the obese mouse model was successfully established (Fig. 5C). The food intake in the
HFD group was always lower than that of the CD group. The differences could be attributed to the higher caloric content of HFD $(5.5 \mathrm{~kJ} / \mathrm{g})$ when compared to that of CD (3.8 kJ/g) (Fig. 5D).

\section{PACAP improved reproductive system damage of obese mice}

After successfully establishing the obese mouse model, PACAP was injected intraperitoneally once a day for 4 weeks. As the results show, the body weight of mice in the HFD group mice was much higher than that of the CD group, whereas the high dose $(0.4 \mathrm{mg} / \mathrm{kg})$ PACAPtreated mice with HFD have a much lower average body 

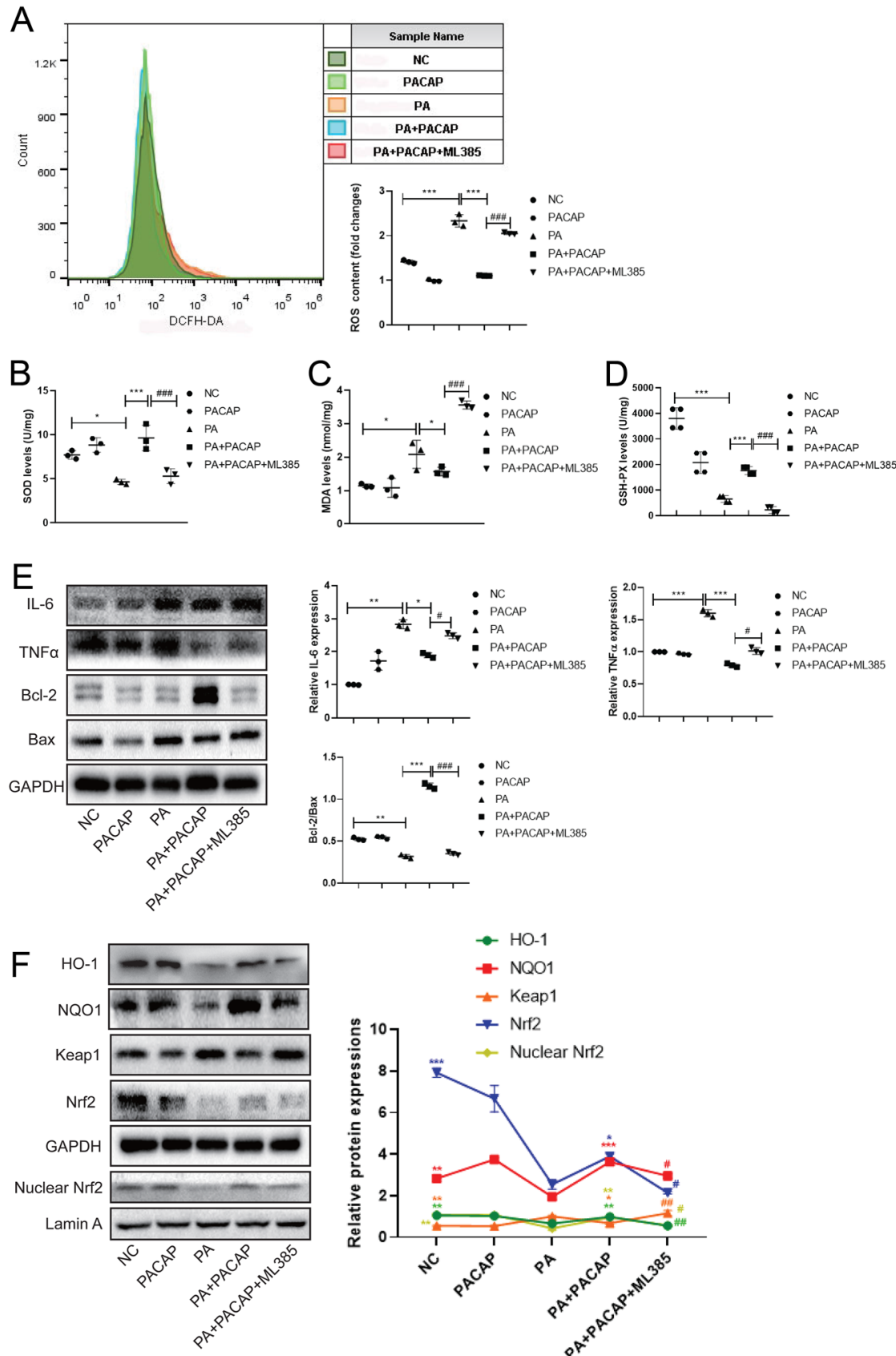

\begin{abstract}
Figure 4
Partial inhibition of Keap1/Nrf2/ARE pathway reversed PACAP-induced spermatogenic cell protection in vitro. (A, B, C and D) ML385 reversed the inhibition effect of PACAP on oxidative stress in GC-2 cells induced by PA. (E) ML385 reversed the inhibition effect of PACAP on inflammation and apoptosis in GC-2 cells induced by PA. (F) ML385 reversed the activation effect of PACAP on Nrf2 signaling pathway in PA-injured GC-2 cells. After incubated with or without $400 \mu \mathrm{M}$ PA for $12 \mathrm{~h}, \mathrm{GC}-2$ cells were preincubated with $5 \mu \mathrm{M}$ ML385 for $24 \mathrm{~h}$ at $37^{\circ} \mathrm{C}$ prior to addition of 100 nM of PACAP. ML385 was used for blocking Nrf2 activation. $* P<0.05, * * P<0.01, * * * P<0.001, \mathrm{NC}$ or PA + PACAP vs PA; $\# P<0.05, \# P<0.01$, $\# \# P<0.001, \mathrm{PA}+\mathrm{PACAP}+\mathrm{ML} 385$ vs PA + PACAP. Data are expressed as mean \pm s.D. A full color version of this figure is available at https://doi. org/10.1530/JOE-20-0316.
\end{abstract}

weight growth and also show a much lower food intake when compared to the other HFD groups (HFD + vehicle, HFD + PACAP $0.1 \mathrm{mg} / \mathrm{kg}$, and HFD + PACAP $0.2 \mathrm{mg} / \mathrm{kg}$ ) (Fig. 6A and B), indicating that PACAP has a weight loss effect by affecting the appetite of mice after it reached a certain concentration. The weight of epididymal adipose can reflect the degree of obesity. The high dose $(0.4 \mathrm{mg} / \mathrm{kg})$ PACAP-treated HFD mice were found to have a much lower epididymal adipose weight than that of HFD mice (Fig. 6C). Testicular index (testicular weight/body weight) is one of the criteria for judging male infertility. It could be seen that high dose (0.4 mg/kg) PACAP could significantly increase testicular index compared to HFD + Vehicle group (Fig. 6D). Clinically obese patients are often accompanied by high blood lipids and high blood lipids can cause male sexual dysfunction. The results show that high dose $(0.4 \mathrm{mg} / \mathrm{kg})$ PACAP could effectively improve four lipids (TG, TC, LDL-C, HDL-C) in serum of high-fat diet mice (Fig. 6E). Obesity often leads to endocrine disorders, the lowered $\mathrm{T}$, and increased $\mathrm{E} 2$ in the HFD group could destroy the negative feedback loop of 
$C D$ HFD
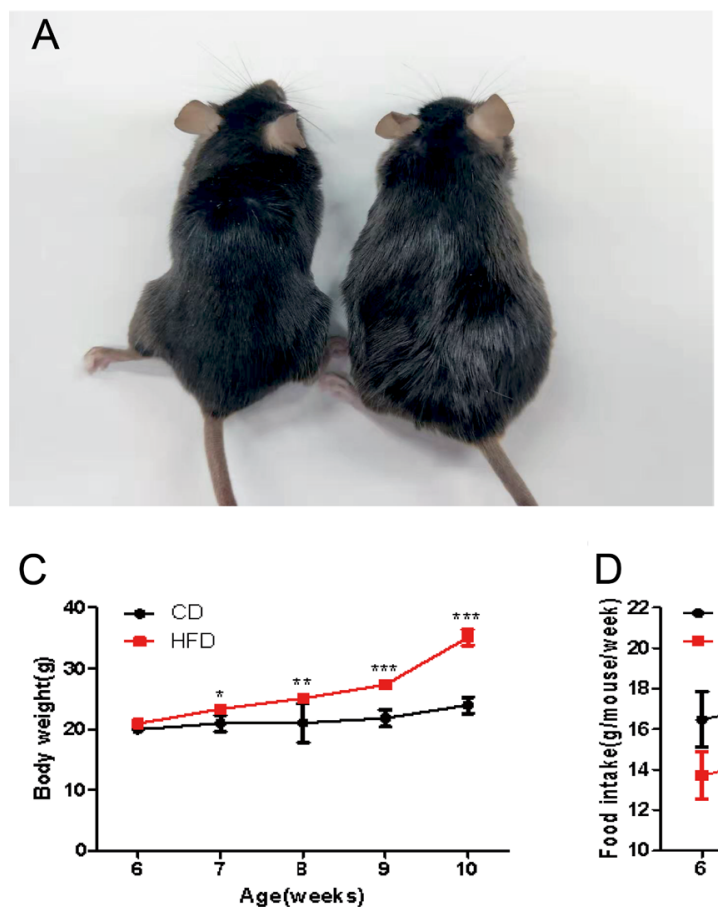
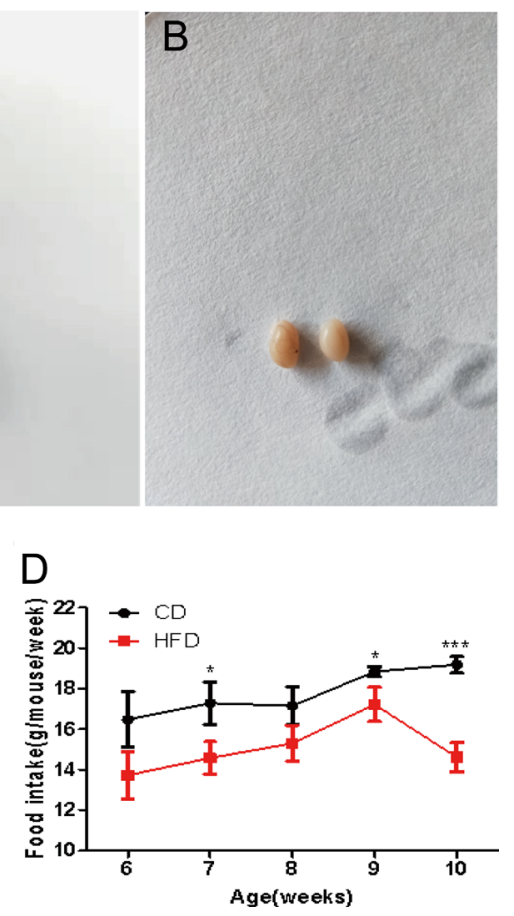

\section{Figure 5}

Description of the obese mouse model fed by HFD for 4 weeks. (A) Representative appearance of HFD and CD mice; (B) Representative testicular appearance of HFD and CD mice; (C) Body weight comparison between HFD and CD groups mice; (D) Weekly food intake between HFD and CD mice. $* P<0.05$, $\star * P<0.01, * * * P<0.001, \mathrm{HFD}$ vs CD. Data are expressed as mean \pm S.D. A full color version of this figure is available at https://doi.org/10.1530/ JOE-20-0316. the hypothalamus-pituitary-testis (HPT) axis, thus reducing sperm production. In this study, HFD mice exhibited the lowest levels of T, FSH and LH, and the highest levels of E2, while PACAP significantly increased $\mathrm{T}$ and decreased $\mathrm{E} 2$ and increased FSH and LH secretion in a dose-dependent manner (Fig. 6F). The improvement in the volume of epididymal adipose cells in the HFD + Vehicle group also show a PACAP dose dependency (Fig. 6G). Normal testicular tissue structure is a prerequisite for maintaining reproductive function. The testicular H\&E staining results show that obese mice have an abnormal testicular structure compared to that of normal mice in the CD group. With the increase of PACAP concentration, the degree of testicular damage has gradually recovered, the thickness of spermatogenic epithelium has visibly restored, and the number of spermatogenic cells has increased (Fig. 6H). We have extracted the protein of the testis tissue of each group and the Western blot results indicated that PACAP could activate Nrf2 signaling pathway (Fig. 6I).

In summary, whether it was to slow down the mice weight gain or to improve the testicular oxidative stress damage induced by obesity, high dose $(0.4 \mathrm{mg} / \mathrm{kg})$ PACAP show the best effect. Therefore, we chose the concentration of $0.4 \mathrm{mg} / \mathrm{kg}$ PACAP to complete subsequent experimental studies.
PACAP promotes testicular Nrf2 expression and activates Nrf2/Keap1/ARE signaling pathway to protect mice testicular injury

To examine whether the protective role of PACAP in obesity-induced testicular oxidative stress was mediated via activation of $\mathrm{Nrf} 2$, the mice received an intratesticular injection containing LV-Nrf2-shRNA for Nrf2 knockdown. The protein expression level of Nrf2 in Nrf2 shRNA group transfected with target lentivirus was significantly lower than that in non-transfected group not transfected with lentivirus or in Ctrl shRNA group transfected with scramble lentivirus after injecting Nrf2 lentivirus in the mice testes (Fig. 7A). It indicated that lentivirus successfully transfected spermatogenic cells in mice testis and knocked down Nrf2 gene. We also collected semen samples from mice to detect the ROS levels. The results show that the ROS levels in the sperm of the HFD group were much higher than those in the NC group. After PACAP intervention, the ROS content in the sperm of the mice decreased, but the inhibitory effect of PACAP disappeared after knocking down Nrf2 (Fig. 7B). By using H\&E staining, we found that the epididymal adipose volume in $\mathrm{HFD}+\mathrm{PACAP}+\mathrm{shNrf2}$ group was larger compared with $\mathrm{HFD}+\mathrm{PACAP}+$ shCtrl group after knocking down Nrf2 gene (Fig. 7C), and the testicular 

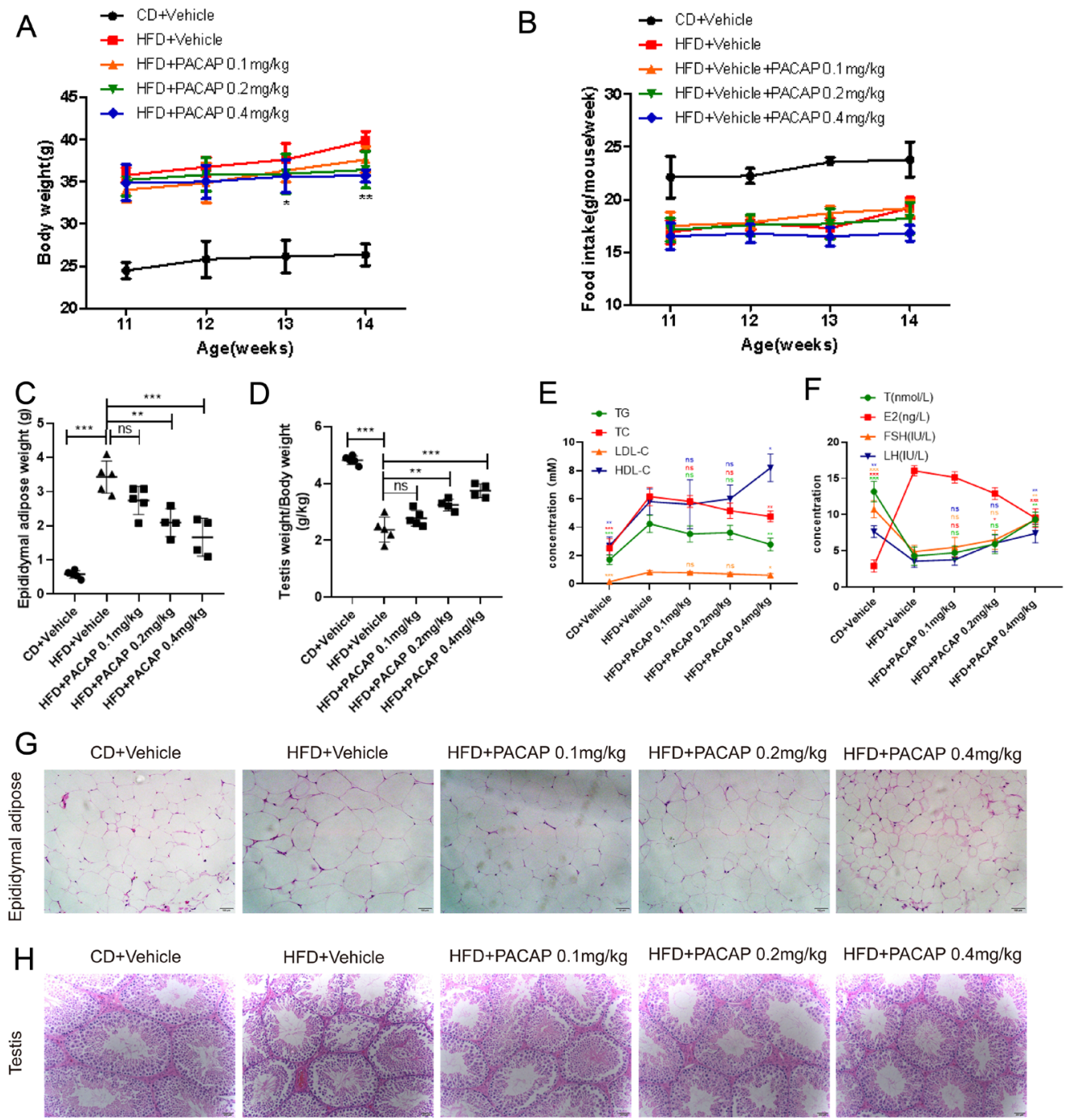

HFD+Vehicle

HFD+PACAP $0.1 \mathrm{mg} / \mathrm{kg}$
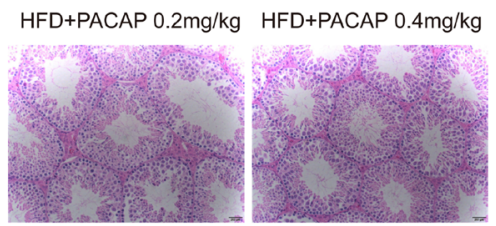
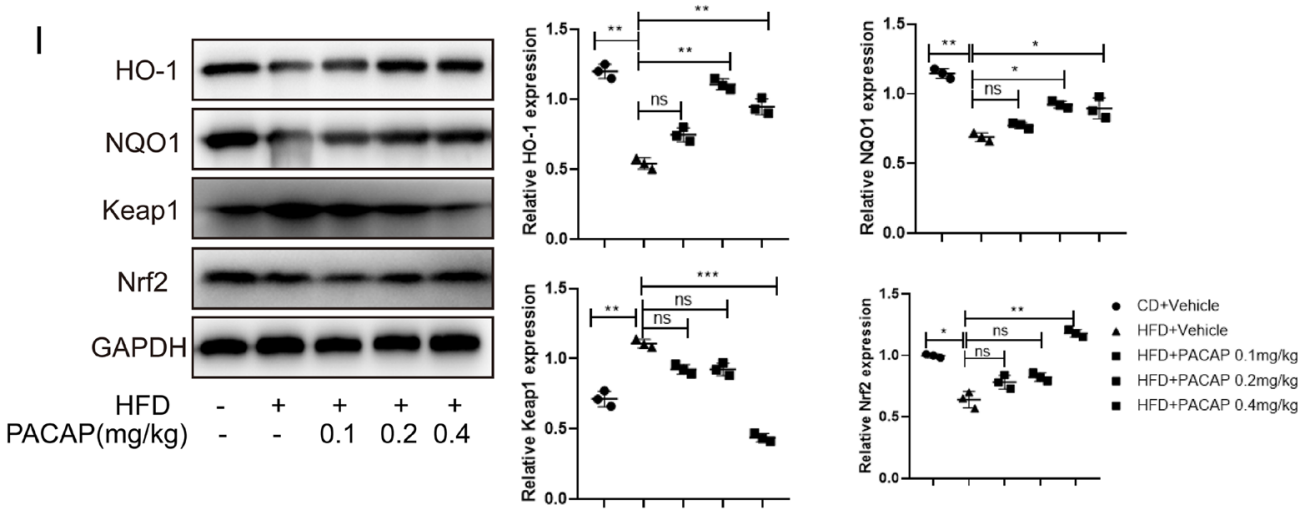

\section{Figure 6}

PACAP improved reproductive system damage of obese mice. (A and B) Body weight and food intake curves of male mice fed with CD or HFD, and treated with or without $0.1,0.2$ and $0.4 \mathrm{mg} / \mathrm{kg} / \mathrm{day}$ of PACAP throughout 4 weeks. ${ }^{*} P<0.05, * \star P<0.01$, HFD+PACAP $0.4 \mathrm{mg} / \mathrm{kg}$ vs HFD + Vehicle. (C and D) Epididymal adipose weight and the ratio of testes/body weight after a 4-week PACAP supplement. (E and F) Serum levels of TG, TC, LDL-C, HDL-C, T, E2, FSH, and LH were detected after mice received 4 weeks of PACAP treatment via i.p. injection. (G) Histological morphology of epididymal adipose stained with H\&E staining. Scale bars $=100 \mu \mathrm{m}$. (H) Histological morphology of testes stained with H\&E staining. Scale bars $=200 \mu \mathrm{m}$. (I) PACAP activates Nrf2 signaling pathway-related protein expression in testes of obese mice. $* P<0.05$, $* * P<0.01, * \star * P<0.001, \mathrm{CD}+$ Vehicle or HFD + PACAP $0.2 \mathrm{mg} / \mathrm{kg}$ or HFD + PACAP 0.4 $\mathrm{mg} / \mathrm{kg}$ vs HFD + Vehicle. Data are expressed as mean \pm S.D. A full color version of this figure is available at https://doi.org/10.1530/JOE-20-0316. 
A
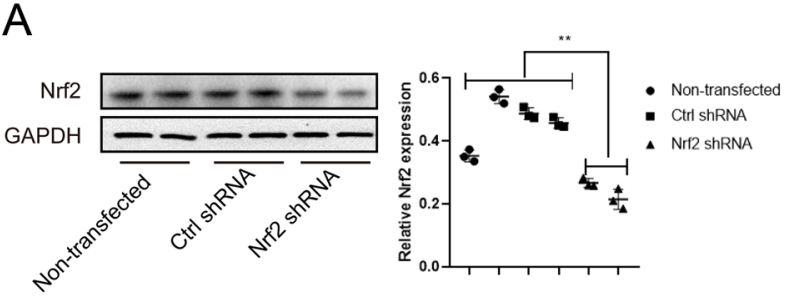

C

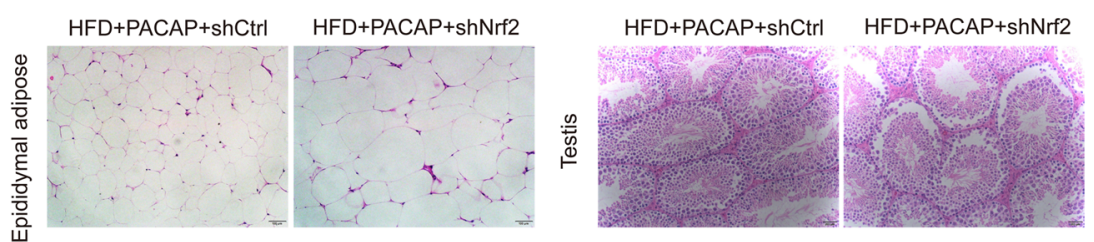

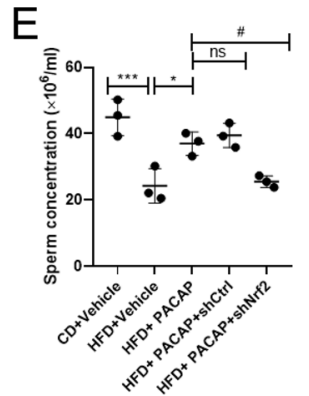

$\mathrm{H}$

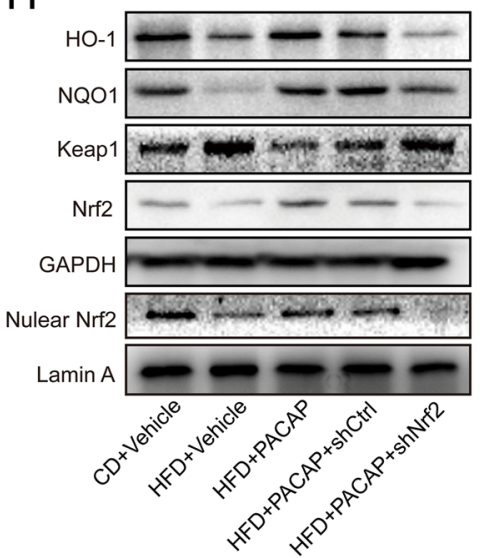

$\mathrm{F}$

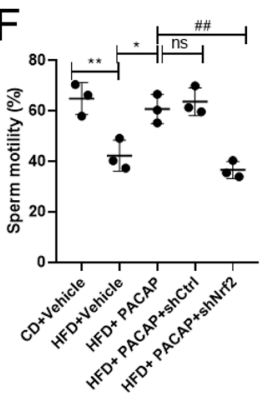

B要

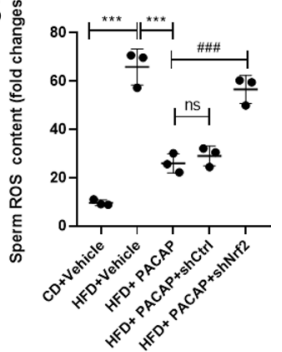

$\mathrm{D}$

G

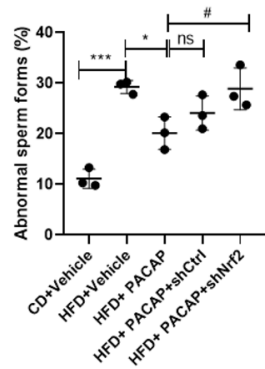

Figure 7

PACAP does not attenuate testicular oxidative damage in HFD mice with testicular knockdown of Nrf2. (A) The knockdown efficiency of Nrf2 in LV-Nrf2-shRNA transfected mouse testis was examined by Western blot. $* * P<0.01$, nontransfected or Ctrl shRNA vs Nrf2 shRNA. (B) PACAP treatment reduced ROS levels in the sperm of the HFD mice via Nrf2. (C) HE staining to observe the effect of Nrf2 lentivirus on epididymal adipose. Scale bars $=100 \mu \mathrm{m}$. (D) HE staining to observe the effect of Nrf2 lentivirus on testes. Scale bars $=200 \mu \mathrm{m}$. (E, F and G) PACAP treatment improved sperm characteristics in HFD mice via Nrf2. (H) Western blot detection of Nrf2 pathway-related protein expression in testes after knocking down Nrf2. $* P<0.05, * * P<0.01$, $* * * P<0.001, \mathrm{CD}+$ Vehicle or HFD + PACAP vs HFD + Vehicle; $\# P<0.05, \# P<0.01, \# \# P<0.001$, HFD + PACAP + shNrf2 vs HFD + PACAP. Data are expressed as mean \pm S.D. A full color version of this figure is available at https://doi.org/10.1530/ JOE-20-0316. tissue structure was significantly destroyed (Fig. 7D) in HFD + PACAP + shNrf2 group, indicating that knockdown of Nrf2 reversed the protective effect of PACAP on testis and epididymis. Sperm parameters analysis show that the sperm concentration, sperm motility, and abnormal sperm ratio in the HFD group recovered after PACAP treatment. Knockdown of Nrf2 in the testis weakened that protective effect of PACAP, indicating that Nrf2 played an important role in improving the semen quality of obese mice by PACAP (Fig. 7E, F and G). In addition, knockdown of $\mathrm{Nrf} 2$ in the testis reduced the expression of Nrf2 pathwayrelated proteins and inhibited the antioxidant signaling pathway in mice testis, suggesting that the Nrf2 pathway mediated the inhibitory effect of PACAP on testicular oxidative stress (Fig. 7H).

Mechanism of PACAP regulating obesity-induced spermatogenic disorders (Fig. 8).

\section{Discussion}

Excessive fat accumulation leads to obesity. In an endocrine organ, fat secretes inflammatory causing factors and produces ROS that attacks testicular spermatogenic 


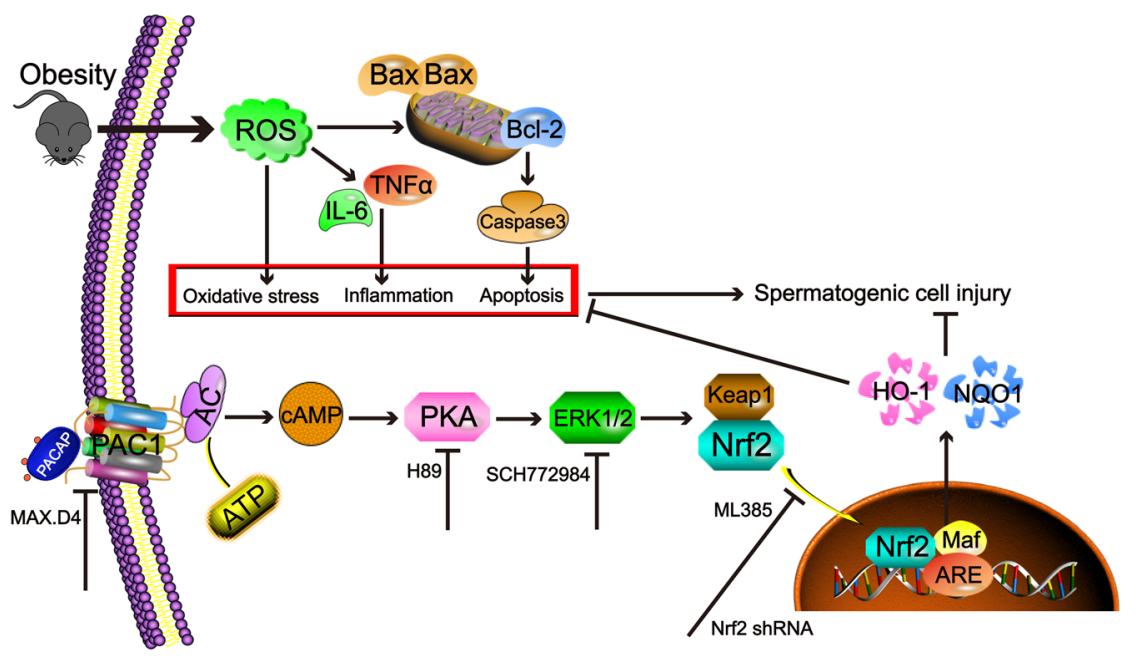

\section{Figure 8}

Schematic diagram of PACAP selectively binding to PAC1 inhibited obesity-induced cell oxidative injury and apoptosis via Keap1/Nrf2/ARE pathway. PACAP selectively binds to the PAC1 receptor and activates PKA/ERK and activated ERK promotes the expression of Nrf2. Nrf2 enters the nucleus and combines with the antioxidant response element (ARE) to activate the expression of downstream HO-1 and NQO1, increasing the level of SOD and GPX, thereby inhibiting ROS-induced oxidative stress damage, apoptosis and inflammation, and improving high-fat-induced germ cell damage. cAMP-response elementbinding protein; PAC1, PACAP type I receptor; PACAP, pituitary adenylate cyclase-activating peptide; PKA, protein kinase A; ERK, extracellular regulated kinase; Nrf2, nuclear factor-erythroid 2-related factor-2. A full color version of this figure is available at https://doi.org/10.1530/ JOE-20-0316.

cells and causes apoptosis of spermatogenic cells. Palmitic acid (PA) is one of the highest free fatty acids in serum, and elevated levels of serum free fatty acids are closely related to obesity. PA-induced cell model in vitro can mimic the high-fat environment in obesity-related or type 2 diabetes patients. In this study, PA was used to establish a GC-2 high-fat injury cell model to simulate the obese environment in vivo. Whereafter we found that PACAP can improve obesity-induced germ cell damage at the cellular level in vitro.

Oxidative stress plays an important role in nutritional obesity-related infertility. In the study of obesity and related diseases such as diabetes and cardiovascular disease, it was found that the level of oxidative stress markers in these patients is higher than that of normal population (Halliwell \& Cross 1994), so it was speculated that oxidative stress may be an important pathogenesis of obesity-induced reproductive disorders. Obesityrelated patients often produce more ROS, and the body's antioxidant, anti-apoptotic and anti-inflammatory abilities decline. When ROS accumulates in the body beyond the antioxidant defense capacity of spermatogenic cells, it induces spermatogenic cells to undergo oxidative stress damage, resulting in apoptosis of spermatogenic cells (Seo et al. 2014). During the process of spermatogenic cell apoptosis, many systems and substances are activated, which in turn leads to dysregulation of the inflammatory response (Matsumaru \& Motohashi 2020). Studies have shown that nutritional obesity can significantly increase the apoptosis of testicular spermatogonia and spermatocytes in adolescent rats with conversion disorder, which reduces the generation of sperm cells and sperm (Bieniek et al. 2016). In our experiments, high-fat (PA) increased ROS levels and cell apoptosis in spermatocyte GC-2, resulting in a decrease in the number of mature spermatozoa. It may be one of the reasons for poor spermatogenic ability of obesity-related patients. Therefore, improving the antioxidant capacity of the reproductive system in obesity-related patients can reduce ROS-induced apoptosis of spermatogenic cells and prevent the occurrence of obesity-induced infertility. As a multifunctional bioactive peptide secreted by the pituitary gland, PACAP has various biological functions such as regulating glycolipid metabolism, neuroprotection, antioxidation, anti-apoptosis and anti-inflammation (Dohi et al. 2002). Our results show that the intracellular ROS level decreased significantly after PACAP treatment, and GPX and SOD levels also increased, while the MDA level and the number of apoptotic cells decreased. In addition, PACAP could also reduce the expression of apoptosisrelated proteins and inflammatory factors in cells. These results indicated that PACAP protected the normal function of germ cells by reducing oxidative stress in spermatogenic cells induced by high fat, inhibiting ROSinduced cell apoptosis and inflammatory damage.

It has been reported that high-fat and high-calorie diets can cause nutritional obesity in rats, abnormal glucose and lipid metabolism, sex hormone disorders, oxidative stress in the body and local high inflammatory reaction of the testis, etc., caused by obesity destroy testicular spermatogenesis function of obese rats (Bieniek et al. 2016). Studies have shown that PACAP could suppress appetite and reduce the weight of rats (Iemolo et al. 2015). Another study confirmed that PACAP inhibited 
obesity-induced apoptosis of testicular spermatogenic cells by inactivating p53-mediated mitochondrial apoptosis signaling pathway (Yan et al. 2020). Our study found that under the effect of PACAP, high-fat-induced mouse body weight and epididymal fat increase were effectively controlled, testicular weight increased significantly, blood lipids (TG, TC, LDL-C and HDL-C) and sex hormones (T, E2, FSH and LH) levels have been significantly improved, and fat and sex hormone metabolism disorders have been effectively improved. In addition, PACAP reduced the pathological damage of testicular tissue induced by obesity. These results indicated that PACAP could improve the testicular reproductive function of obese mice from multiple levels such as improving obese body weight, fat and sex hormone metabolism, epididymis and testicular structure.

PACAP could also activate Nrf2 pathway-related proteins expression. Nrf2 is a key regulator of oxidative stress in cells, and its activity is mainly negatively regulated by Keap1. Nrf2 regulates the transcription of genes containing antioxidants in the promoter by interacting with the antioxidant response element (ARE). Mice lacking Nrf2 reduced the constitutive and inducible expression of SOD, CAT, and GSH (Wild et al. 1999, Nguyen et al. 2003). Previous research have shown that Nrf2 gene knockout mice could accelerate the reduction of the testicular and epididymal antioxidant capacity, thereby generating oxidative stress, destroying spermatogenesis and affecting the reproductive capacity of mice (Nakamura et al. 2010). According to relevant literature reports, Nrf2--- male mice testis weight, testis and epididymal sperm counts were agerelated declination, and compared with WT mice aged 2-7 months, Nrf2-I- male mice have increased spermatogenic tubule vacuolation. In addition, GSH levels, antioxidant gene expression and enzyme activity in $\mathrm{Nrf}^{-/-}$male testes and epididymis were lower than that in $\mathrm{Nrf2} 2^{+/+}$ male (Chan \& Kwong 2000). Yamamoto et al. found that decreased testicular antioxidant capacity led to increased testicular oxidative stress, resulting in germ cell apoptosis, reduced sperm production, and ultimately reduced Nrf2/-male fertility (Yamamoto et al. 2004). The previously mentioned research show that Nrf2 was an important factor for spermatogenesis, and the lack of transcription factor Nrf2 led to severe obesity-related spermatogenesis obstruction. Therefore, Nrf2 signaling could be used as a therapeutic target for obesity-induced infertility, so understanding the relationship between PACAP and Nrf2 signaling would promote the development of new pharmacological insights to treat infertility associated with nutritional obesity.
We have demonstrated that at the cellular level the Keap1/Nrf2/ARE pathway mediated the protective effect of PACAP on high-fat-induced germ cell damage. PACAP has three main receptor subtypes of PAC1, VPAC1 and VPAC2. PACAP binds to different receptors and triggers different signaling pathways to play different biological functions (Vaudry et al. 2009). However, it remains unclear which receptor is involved in the protective effect of PACAP on germ cells. Our receptor blocking experiment results indicated that PACAP selectively bound to the PAC1 receptor, activated the Nrf2 signaling pathway, and improved high-fat-induced GC-2 cell damage. More and more evidences indicated that PACAP was mainly mediated by PAC1 receptor and exerted antioxidant and antiapoptotic effects (Seaborn et al. 2011). PACAP selectively bound to the PAC1 receptor, activated adenylate cyclase (AC), and catalyzed the conversion of ATP to cAMP, which in turn activated cAMP-dependent protein kinase A (PKA). Phosphorylated PKA could make intracellular phosphorylation of various proteins, such as MEK, ERK, etc., which produced antioxidant and antiapoptotic effects (Gräs et al. 2000). It has been found that phosphorylated ERK could directly recognize the antioxidant regulatory factor $\mathrm{Nrf} 2$ and activate $\mathrm{Nrf} 2$ to enter the nucleus, thus activating Keap1/Nrf2/ARE signaling pathway (Wei et al. 2018). Our experimental results show that PACAP upregulated the expression levels of p-PKA and p-ERK in GC-2 cells with high-fat injury. The upregulated p-ERK further promoted the expression of downstream Nrf2 protein. Subsequently, we used MAX. D4, H89, and SCH772984 to pretreat cells and found that MAX.D4, H89, and SCH772984 all effectively inhibited PACAP-induced Nrf2 upregulation. These data indicated that PACAP selectively bound to PAC1 and activated the PKA/ERK/Nrf2 signaling pathway, thereby promoting the repair of high-fat injured cells.

In animal level experiments, our Western blot results show that PACAP could promote the expression of Nrf2 protein and downstream proteins HO-1 and NQO1 and downregulate the expression of Keap1 in the testis tissue of obese mice, indicating that PACAP might activate the expression of downstream proteins HO-1 and NQO1, activate the antioxidant signaling pathway, inhibit oxidative damage and apoptosis in testicular spermatogenic cells induced by obesity, and improve the fertility of obese mice by upregulating Nrf2 expression. These protective effects of PACAP were weakened after suppressing Nrf2 activity or knocking down the Nrf2 gene.

In summary, the current study revealed three main findings. First, we have demonstrated that obesity- 
induced male reproductive damage was related to the decreased activity of Nrf2. Secondly, a decrease in Nrf2 levels led to an increase in ROS levels, induced oxidative stress, and thus enhanced the apoptotic and inflammatory effects in spermatogenic cells. Thirdly, PACAP was shown to selectively bind to the PAC1 receptor and activate the downstream PKA/ERK/Nrf2 signaling pathway to protect against obesity-induced male reproductive impairment (Fig. 8). Our findings collectively demonstrated that the Keap1/Nrf2/ARE signaling pathway played a crucial role in restoring the fertility of men with obesity after PACAP treatment. However, more research is necessary to understand the potential mechanisms of the anti-obesity, anti-oxidation, anti-apoptosis and anti-inflammation effects of PACAP. Nevertheless, our results laid the foundation for exploring PACAP as a promising candidate drug for male infertility caused by obesity.

\section{Declaration of interest}

The authors declare that there is no conflict of interest that could be perceived as prejudicing the impartiality of the research reported.

\section{Funding}

This work was supported by grants from the National Natural Science Foundation of China (No. 81373314, 81741130), the Natural Science Foundation of Guangdong Province, China (No. 2019A1515011866), Guangzhou Municipal Science and Technology Program (No. 201707010245, 201704020117).

\section{Author contribution statement}

Yi Ma and Wailan Shan conceived and designed the research. Wailan Shan, Zixian Wang, Xiaohua Lu inquired and collected information. Wailan Shan, Shiyin Lu, Jia Feng researched and performed the research. Wailan Shan, Biqian Ou, Huixian Li processed and analysed the data. Wailan Shan, Jia Feng and Yi Ma wrote, reviewed and/or revised the manuscript. Wailan Shan, Jia Feng and Xiaohua Lu contributed equally to this work.

\section{References}

Agarwal A, Rana M, Qiu E, AlBunni H, Bui AD \& Henkel R 2018 Role of oxidative stress, infection and inflammation in male infertility. Andrologia 50 e13126. (https://doi.org/10.1111/and.13126)

Aitken RJ, Buckingham DW, Carreras A \& Irvine DS 1996 Superoxide dismutase in human sperm suspensions: relationship with cellular composition, oxidative stress, and sperm function. Free Radical Biology and Medicine 21 495-504. (https://doi.org/10.1016/08915849(96)00119-0)

Arimura A 1992 Receptors for pituitary adenylate cyclase-activating polypeptide: comparison with vasoactive intestinal peptide receptors. Trends in Endocrinology and Metabolism 3 288-294. (https://doi. org/10.1016/1043-2760(92)90139-r)
Bachir BG \& Jarvi K 2014 Infectious, inflammatory, and immunologic conditions resulting in male infertility. Urologic Clinics of North America 41 67-81. (https://doi.org/10.1016/j.ucl.2013.08.008)

Bieniek JM, Kashanian JA, Deibert CM, Grober ED, Lo KC, Brannigan RE, Sandlow JI \& Jarvi KA 2016 Influence of increasing body mass index on semen and reproductive hormonal parameters in a multiinstitutional cohort of subfertile men. Fertility and Sterility $\mathbf{1 0 6}$ 1070-1075. (https://doi.org/10.1016/j.fertnstert.2016.06.041)

Caballero B 2007 The global epidemic of obesity: an overview. Epidemiologic Reviews 29 1-5. (https://doi.org/10.1093/epirev/ $\mathrm{mxm012)}$

Cabler S, Agarwal A, Flint M \& du Plessis SS 2010 Obesity: modern man's fertility nemesis. Asian Journal of Andrology 12 480-489. (https://doi. org/10.1038/aja.2010.38)

Chan JY \& Kwong M 2000 Impaired expression of glutathione synthetic enzyme genes in mice with targeted deletion of the Nrf2 basic-leucine zipper protein. Biochimica et Biophysica Acta 1517 19-26. (https://doi. org/10.1016/s0167-4781(00)00238-4)

Dejda A, Jolivel V, Bourgault S, Seaborn T, Fournier A, Vaudry H \& Vaudry D 2008 Inhibitory effect of PACAP on caspase activity in neuronal apoptosis: a better understanding towards therapeutic applications in neurodegenerative diseases. Journal of Molecular Neuroscience 36 26-37. (https://doi.org/10.1007/s12031-008-9087-1)

Dohi K, Mizushima H, Nakajo S, Ohtaki H, Matsunaga S, Aruga T \& Shioda S 2002 Pituitary adenylate cyclase-activating polypeptide (PACAP) prevents hippocampal neurons from apoptosis by inhibiting JNK/SAPK and p38 signal transduction pathways. Regulatory Peptides 109 83-88. (https://doi.org/10.1016/s01670115(02)00190-8)

Douiri S, Bahdoudi S, Hamdi Y, Cubì R, Basille M, Fournier A, Vaudry H, Tonon MC, Amri M, Vaudry D, et al. 2016 Involvement of endogenous antioxidant systems in the protective activity of pituitary adenylate cyclase-activating polypeptide against hydrogen peroxideinduced oxidative damages in cultured rat astrocytes. Journal of Neurochemistry 137 913-930. (https://doi.org/10.1111/jnc.13614)

Durairajanayagam D, Agarwal A, Ong C \& Prashast P 2014 Lycopene and male infertility. Asian Journal of Andrology 16 420-425. (https://doi. org/10.4103/1008-682X.126384)

Galliano D \& Bellver J 2013 Female obesity: short- and long-term consequences on the offspring. Gynecological Endocrinology 29 626-631. (https://doi.org/10.3109/09513590.2013.777420)

Gräs S, Hedetoft C, Pedersen SH \& Fahrenkrug J 2000 Pituitary adenylate cyclase-activating peptide stimulates acute progesterone production in rat granulosa/lutein cells via two receptor subtypes. Biology of Reproduction 63 206-212. (https://doi.org/10.1095/ biolreprod63.1.206)

Halliwell B \& Cross CE 1994 Oxygen-derived species: their relation to human disease and environmental stress. Environmental Health Perspectives 102 (Supplement 10) 5-12. (https://doi.org/10.1289/ ehp.94102s105)

Hammoud AO, Wilde N, Gibson M, Parks A, Carrell DT \& Meikle AW 2008 Male obesity and alteration in sperm parameters. Fertility and Sterility 90 2222-2225. (https://doi.org/10.1016/j. fertnstert.2007.10.011)

Iemolo A, Ferragud A, Cottone P \& Sabino V 2015 Pituitary adenylate cyclase-activating peptide in the central amygdala causes anorexia and body weight loss via the melanocortin and the TrkB systems. Neuropsychopharmacology 40 1846-1855. (https://doi.org/10.1038/ npp.2015.34)

Itoh K, Mimura J \& Yamamoto M 2010 Discovery of the negative regulator of Nrf2, Keap1: a historical overview. Antioxidants and Redox Signaling 13 1665-1678. (https://doi.org/10.1089/ ars.2010.3222)

Jeulin C, Soufir JC, Weber P, Laval-Martin D \& Calvayrac R 1989 Catalase activity in human spermatozoa and seminal plasma. Gamete Research 24 185-196. (https://doi.org/10.1002/mrd.1120240206) https://joe.bioscientifica.com

https://doi.org/10.1530/JOE-20-0316 (c) 2021 Society for Endocrinology Published by Bioscientifica Ltd. Printed in Great Britain 
Kensler TW, Wakabayashi N \& Biswal S 20072007 cell survival responses to environmental stresses via the Keap1-Nrf2-ARE pathway. Annual Review of Pharmacology and Toxicology 47 89-116. (https://doi. org/10.1146/annurev.pharmtox.46.120604.141046)

Khodagholi F \& Tusi SK 2011 Stabilization of Nrf2 by tBHQ prevents LPSinduced apoptosis in differentiated PC12 cells. Molecular and Cellular Biochemistry 354 97-112. (https://doi.org/10.1007/s11010-011-0809-2)

Kley HK, Deselaers T, Peerenboom H \& Krüskemper HL 1980 Enhanced conversion of androstenedione to estrogens in obese males. Journal of Clinical Endocrinology and Metabolism 51 1128-1132. (https://doi. org/10.1210/jcem-51-5-1128)

Kuwabara Y, Horie T, Baba O, Watanabe S, Nishiga M, Usami S, Izuhara M, Nakao T, Nishino T, Otsu K, et al. 2015 MicroRNA-451 exacerbates lipotoxicity in cardiac myocytes and high-fat diet-induced cardiac hypertrophy in mice through suppression of the LKB1/AMPK pathway. Circulation Research 116 279-288. (https://doi.org/10.1161/ CIRCRESAHA.116.304707)

Landry D, Cloutier F \& Martin LJ 2013 Implications of leptin in neuroendocrine regulation of male reproduction. Reproductive Biology 13 1-14. (https://doi.org/10.1016/j.repbio.2012.12.001)

Liu Y \& Ding Z 2017 Obesity, a serious etiologic factor for male subfertility in modern society. Reproduction 154 R123-R131. (https:// doi.org/10.1530/REP-17-0161)

Liu Y, Jiang XL, Liu Y, Jiang DS, Zhang Y, Zhang R, Chen Y, Yang Q, Zhang XD, Fan GC, et al. 2014 Toll-interacting protein (Tollip) negatively regulates pressure overload-induced ventricular hypertrophy in mice. Cardiovascular Research 101 87-96. (https://doi. org/10.1093/cvr/cvt232)

Liu Z, Li P, Zhao ZH, Zhang Y, Ma ZM \& Wang SX 2016 Vitamin B6 prevents endothelial dysfunction, insulin resistance, and hepatic lipid accumulation in Apoe (-/-) mice fed with high-fat diet. Journal of Diabetes Research 2016 1748065. (https://doi. org/10.1155/2016/1748065)

Liu B, Shen LJ, Zhao TX, Sun M, Wang JK, Long CL, He DW, Lin T, Wu SD \& Wei GH 2020 Automobile exhaust-derived PM(2.5) induces bloodtestis barrier damage through ROS-MAPK-Nrf2 pathway in Sertoli cells of rats. Ecotoxicology and Environment Safety 189 110053. (https://doi. org/10.1016/j.ecoenv.2019.110053)

Lu JC, Huang YF \& Lü NQ 2010 WHO Laboratory Manual for the examination and processing of human semen: its applicability to andrology laboratories in China. Zhonghua Nan Ke Xue 16 867-871.

Manco M, Mingrone G, Greco AV, Capristo E, Gniuli D, De Gaetano A \& Gasbarrini G 2000 Insulin resistance directly correlates with increased saturated fatty acids in skeletal muscle triglycerides. Metabolism: Clinical and Experimental 49 220-224. (https://doi.org/10.1016/s00260495(00)91377-5)

Marzec-Wróblewska U, Kamiński P, Lakota P, Szymański M, Wasilow K, Ludwikowski G, Kuligowska-Prusińska M, Odrowąż-Sypniewska G, Stuczyński T \& Michałkiewicz J 2011 Zinc and iron concentration and SOD activity in human semen and seminal plasma. Biological Trace Element Research 143 167-177. (https://doi.org/10.1007/s12011-0108868-x)

Matsumaru D \& Motohashi H 2020 From germ cells to neonates: the beginning of life and the KEAP1-NRF2 system. Journal of Biochemistry 167 133-138. (https://doi.org/10.1093/jb/mvz070)

Meigs JB, Larson MG, Fox CS, Keaney JF, Jr, Vasan RS \& Benjamin EJ 2007 Association of oxidative stress, insulin resistance, and diabetes risk phenotypes: the Framingham Offspring Study. Diabetes Care 30 2529-2535. (https://doi.org/10.2337/dc07-0817)

Meseguer M, Martínez-Conejero JA, Muriel L, Pellicer A, Remohí J \& Garrido N 2007 The human sperm glutathione system: a key role in male fertility and successful cryopreservation. Drug Metabolism Letters 1 121-126. (https://doi.org/10.2174/187231207780363633)

Nakamura BN, Lawson G, Chan JY, Banuelos J, Cortés MM, Hoang YD, Ortiz L, Rau BA \& Luderer U 2010 Knockout of the transcription factor NRF2 disrupts spermatogenesis in an age-dependent manner.
Free Radical Biology and Medicine 49 1368-1379. (https://doi. org/10.1016/j.freeradbiomed.2010.07.019)

Nguyen T, Sherratt PJ \& Pickett CB 2003 Regulatory mechanisms controlling gene expression mediated by the antioxidant response element. Annual Review of Pharmacology and Toxicology 43 233-260. (https://doi.org/10.1146/annurev.pharmtox.43.100901.140229)

Palmer NO, Bakos HW, Fullston T \& Lane M 2012 Impact of obesity on male fertility, sperm function and molecular composition. Spermatogenesis 2 253-263. (https://doi.org/10.4161/spmg.21362)

Ramírez-Torres MA, Carrera A \& Zambrana M 2000 High incidence of hyperestrogenemia and dyslipidemia in a group of infertile men. Ginecologia y Obstetricia de Mexico 68 224-229.

Reglodi D, Cseh S, Somoskoi B, Fulop BD, Szentleleky E, Szegeczki V, Kovacs A, Varga A, Kiss P, Hashimoto H, et al. 2018 Disturbed spermatogenic signaling in pituitary adenylate cyclase activating polypeptide-deficient mice. Reproduction 155 129-139. (https://doi. org/10.1530/REP-17-0470)

Sato M, Ishikawa A \& Kimura M 2002 Direct injection of foreign DNA into mouse testis as a possible in vivo gene transfer system via epididymal spermatozoa. Molecular Reproduction and Development 61 49-56. (https://doi.org/10.1002/mrd.1130)

Seaborn T, Masmoudi-Kouli O, Fournier A, Vaudry H \& Vaudry D 2011 Protective effects of pituitary adenylate cyclase-activating polypeptide (PACAP) against apoptosis. Current Pharmaceutical Design 17 204-214. (https://doi. org/10.2174/138161211795049679)

Seo H, Lee NH \& Ryu S 2014 Antioxidant and antiapoptotic effects of pine needle powder ingestion and endurance training in high cholesterol-fed rats. Journal of Exercise Nutrition and Biochemistry 18 301-309. (https://doi.org/10.5717/jenb.2014.18.3.301)

Shalaby MA, el-Zorba HY \& Kamel GM 2004 Effect of alpha-tocopherol and simvastatin on male fertility in hypercholesterolemic rats. Pharmacological Research 50 137-142. (https://doi.org/10.1016/j. phrs.2003.10.013)

Shamloul R 2009 The potential role of the heme oxygenase/ carbon monoxide system in male sexual dysfunctions. Journal of Sexual Medicine 6 324-333. (https://doi.org/10.1111/j.17436109.2008.01068.x)

Tanii I, Aradate T, Matsuda K, Komiya A \& Fuse H 2011 PACAP-mediated sperm-cumulus cell interaction promotes fertilization. Reproduction 141 163-171. (https://doi.org/10.1530/REP-10-0201)

Vaudry D, Falluel-Morel A, Bourgault S, Basille M, Burel D, Wurtz O, Fournier A, Chow BK, Hashimoto H, Galas L, et al. 2009 Pituitary adenylate cyclase-activating polypeptide and its receptors: 20 years after the discovery. Pharmacological Reviews 61 283-357. (https://doi. org/10.1124/pr.109.001370)

Wang H, Wan H, Li X, Liu W, Chen Q, Wang Y, Yang L, Tang H, Zhang X, Duan E, et al. 2014 Atg7 is required for acrosome biogenesis during spermatogenesis in mice. Cell Research 24 852-869. (https://doi. org/10.1038/cr.2014.70)

Wei M, Zheng Z, Shi L, Jin Y \& Ji L 2018 Natural polyphenol chlorogenic acid protects against acetaminophen-induced hepatotoxicity by activating ERK/Nrf2 antioxidative pathway. Toxicological Sciences 162 99-112. (https://doi.org/10.1093/toxsci/kfx230)

Wild AC, Moinova HR \& Mulcahy RT 1999 Regulation of gammaglutamylcysteine synthetase subunit gene expression by the transcription factor Nrf2. Journal of Biological Chemistry $\mathbf{2 7 4}$ 33627-33636. (https://doi.org/10.1074/jbc.274.47.33627)

Yada T, Sakurada M, Filipsson K, Kikuchi M \& Ahrén B 2000 Intraperitoneal PACAP administration decreases blood glucose in GK rats, and in normal and high fat diet mice. Annals of the New York Academy of Sciences 921 259-263. (https://doi. org/10.1111/j.1749-6632.2000.tb06974.x)

Yamamoto T, Yoh K, Kobayashi A, Ishii Y, Kure S, Koyama A, Sakamoto T, Sekizawa K, Motohashi H \& Yamamoto M 2004 Identification of polymorphisms in the promoter region of the human NRF2 gene. https://joe.bioscientifica.com https://doi.org/10.1530/JOE-20-0316 (c) 2021 Society for Endocrinology Published by Bioscientifica Ltd. Printed in Great Britain 
Biochemical and Biophysical Research Communications 321 72-79. (https://doi.org/10.1016/j.bbrc.2004.06.112)

Yan Q, Huang H, Lu S, Ou B, Feng J, Shan W, Li H, Wang Z, Hong A \& Ma Y 2020 PACAP ameliorates fertility in obese male mice via PKA/CREB pathway-dependent Sirt1 activation and p53 deacetylation. Journal of Cellular Physiology 235 7465-7483. (https://doi.org/10.1002/jcp.29651) Yoo DY, Kim W, Nam SM, Yoo KY, Lee CH, Choi JH, Won MH,

Hwang IK \& Yoon YS 2011 Reduced cell proliferation and neuroblast differentiation in the dentate gyrus of high fat diet-fed mice are ameliorated by metformin and glimepiride treatment. Neurochemical Research 36 2401-2408. (https://doi.org/10.1007/s11064-011-0566-3) Yu M, Xu M, Liu Y, Yang W, Rong Y, Yao P, Yan H, Wang D \& Liu L 2013 Nrf2/ARE is the potential pathway to protect Sprague-Dawley rats against oxidative stress induced by quinocetone. Regulatory Toxicology and Pharmacology 66 279-285. (https://doi.org/10.1016/j. yrtph.2013.04.005)

Received in final form 29 December 2020

Accepted 21 January 2021

Accepted Manuscript published online 19 February 2021 (c) 2021 Society for Endocrinology Published by Bioscientifica Ltd. Printed in Great Britain 